\title{
Screening diverse soybean genotypes for drought tolerance by membership function value based on multiple traits and drought- tolerant coefficient of yield
}

Chunjuan Yan ${ }^{1}$, Shuhong Song ${ }^{1}$, Wenbin Wang ${ }^{1 *}$, Changling Wang ${ }^{1}$, Haibo Li ${ }^{2}$, Feng Wang ${ }^{3}$, Shengyou $\mathrm{Li}^{1}$ and Xugang Sun ${ }^{1}$

\begin{abstract}
Background: Drought is a major limiting factor seriously influencing worldwide soybean production and its impact on yield, morphological and physiological traits depend on the timing it occurs and the intensity of water shortage. Only limited research has however been conducted on identifying the drought-tolerant genotypes at different growth stages (vegetative growth phase, reproductive growth phase and the whole growth phase) as well as evaluate the effectiveness and reliability of multiple phenotypic and yield-related characteristics in soybean.

Results: Two pot experiments and a 2-year field experiment were conducted to evaluate soybean drought tolerance at different growth stages. The membership function value of drought tolerance (MFVD) was used to identify drought-resistant cultivars during vegetative growth phase and reproductive growth stage; the relative drought index (RDI) of yield was used to assess drought-resistant cultivars during the whole growing period. In this study, regression models built based on MFVD indicated that the variation of drought tolerant coefficient (DC) of R/ S, TRL, LAl and RSR could explain $73.70 \%$ of the total variation at vegetative growth phase. However, higher heritability only found in $L A I$ and RSR, indicating the two traits could serve as reliable criteria for drought evaluation. Similarly, the DC of SPP, YPP, PH, PB, MSNN and STB could explain $94.30 \%$ of the total variation in MFVD according to stepwise multiple linear regression analyses at reproductive growth phase. Thus, these six traits were identified as indicators for screening drought resistance genotypes in soybean. In addition, correlation analysis revealed that the MFVD was significantly positively correlated with the $D C_{R B}, D C_{R / S}, D C_{R S A}, D C_{R S R}$ and $D C_{R B R}$ at vegetative growth phase and $D C_{Y P P}, D C_{S P P}, D C_{R B}$, and $D C_{P B}$ at reproductive growth phase. This indicated that these traits were closely related to the drought resistance of plants.

(Continued on next page)
\end{abstract}

\footnotetext{
* Correspondence: wangwenbin2018@163.com

${ }^{1}$ Crop Institute, Liaoning Academy of Agricultural Science, Shenyang 110161, Liaoning, China
}

Full list of author information is available at the end of the article

(c) The Author(s). 2020 Open Access This article is licensed under a Creative Commons Attribution 4.0 International License, which permits use, sharing, adaptation, distribution and reproduction in any medium or format, as long as you give appropriate credit to the original author(s) and the source, provide a link to the Creative Commons licence, and indicate if changes were made. The images or other third party material in this article are included in the article's Creative Commons licence, unless indicated otherwise in a credit line to the material. If material is not included in the article's Creative Commons licence and your intended use is not permitted by statutory regulation or exceeds the permitted use, you will need to obtain permission directly from the copyright holder. To view a copy of this licence, visit http://creativecommons.org/licenses/by/4.0/ The Creative Commons Public Domain Dedication waiver (http://creativecommons.org/publicdomain/zero/1.0/) applies to the data made available in this article, unless otherwise stated in a credit line to the data. 
(Continued from previous page)

Conclusions: LD24, JD36 and TF31 of vegetative growth phase, and TD37 and LD26 of reproductive growth phase were identified with drought tolerant and highly drought tolerant, respectively. Moreover, 30 accessions with drought tolerance were screened in the field trial and could be applied for the drought resistance of other genotypes by cross-breeding.

Keywords: Soybean, Screening drought tolerance genotypes, Membership function value, Drought-tolerant coefficient

\section{Background}

Soybean (Glycine max L. Merr.), as an indispensable source of protein, oil and micronutrients in human diets and animal fodders, has become a crucial and economical agricultural crop in the world based on its excellent nutritional value and health benefits [1]. However, drought stress, which is the most important abiotic restriction, can have devastating effects on the stability and productivity of soybean in many semi- and arid areas of the world $[2,3]$. It has been extensively reported that drought stress can directly induce a wide range of injury symptoms in plants, such as the inhibition of plant photosynthesis $[4,5]$, increased oxidative [6], and changes in metabolism [7]. Furthermore, drought stress led to the decrease in leaf area, pod yield, plant height, 1000-seed weight, harvest index, seed yield, etc. [8]. It was estimated that about $40 \%$ soybean yield decrease was caused by drought stress [9]. Depending on hybrid characteristics, soybeans use about $450-700 \mathrm{~mm}$ of rain fall during the growing season [10]. Improving the drought resistance of varieties is thus a key measure for reducing yield losses and stabilizing crop production under drought condition. The effects of drought stress on plant depend not only on the characteristics (duration, intensity) of the stress but also on the timing of occurrence relative to the development cycle of the plant. The most critical period for water stress in soybean was the flowering stage and the period following flowering [11]. The yield formation was sensitive when mild water deficit happened during the seedling phase, and became more sensitive to serious water deficit occurring at the flowering-podding phase in soybean [8]. Therefore, it is necessary to evaluate the response of soybean with different genetic germplasms to drought stress at diverse growth stages.

Drought tolerance is defined as the relative yield of a genotype compared to other genotypes subjected to the same drought stress [12]. Although yield was the primary characteristic for measurement of drought resistance on water deficit condition in many crops [13-15], the secondary characteristic might be specifically appropriate to improve selection response to drought stress condition. Relative water content, chlorophyll content, and ascorbic acid could be used as secondary indicators for selecting drought-tolerant genotypes $[16,17]$. In this study, a plant is said to have drought tolerance if it can maintain better phenotypic traits and achieve higher yields under drought conditions. Drought-tolerant coefficient (DC), supply a measure of drought effects based on the reduction of each trait under water stress conditions in comparison to well-watered conditions, and therefore used for identification of drought-tolerant genotypes [18-20]. The membership function value of drought tolerance (MFVD) calculated from DC provided a comprehensive evaluation method for drought resistance of materials based on multi-indicator determination $[21,22]$. According to this method for drought resistance assessment, several studies have reported that some physiological traits such as photosynthetic rate, leaf chlorophyll content, superoxide dismutase (SOD) activity and some yield-related traits such as spikelet number, grain number per spike, grain yield per plant were affected by soil water stress, and have been considered as evaluation parameters of drought resistance in other crops [23-26]. The direct impact on soybean that occurs due to drought stress are the decrease in yield and its component such as number of pods, number of seeds and seed weight [27]. Soybean plants subjected to water stress during flowering and vegetative growth stages had significantly lower total dry matter and yields [28]. Therefore, it is essential to carry out drought tolerance evaluation of soybean phenotypic and yield-related traits.

Plant root architecture has been also reported to be associated with water stress tolerance in various crops [29, 30]. The ability of a plant to modify its root distribution to exploit deeper stored soil water may be an important mechanism to avoid drought [31]. Deep rooting, root length density and root distribution have been identified as drought adaptive traits $[32,33]$ which can be used as selection criteria for drought resistance in other crops. However, the assessment on some important morphological and physiological traits, such as root length, root area and leaf area index (LAI) of soybean lines under different water regimes to examine thoroughly how soybean genotypes respond to drought in terms of these traits has not been clearly demonstrated.

The present investigation was carried out to identify the suitable soybean genotypes for drought tolerance at 
different growth stages combining with the value of membership function (MFVD) and drought-tolerant coefficient (DC). Moreover, this study also aimed to evaluate the use of multiple phenotypic and yield-related traits as secondary indices for drought resistance assessment.

\section{Results}

\section{Response of traits measured and calculated to water} stress

\section{Assessing drought tolerance at vegetative growth stage (Expt. 1)}

The variation was confirmed by the average value, standard deviation (SD) and the drought-tolerant coefficient (DC) of each trait when water was controlled at vegetative growth phase (VGP) were presented in the Table 1. In response to water-stressed (WS) regime, the mean value of 7 traits decreased but the others increased compared with that in the well-watered (WW) regime. Leaf area index (LAI) showed the lowest DC (0.59) which declined by $41.16 \%$, indicating that LAI was the most sensitive trait to water stress in this group of genotypes. In addition, decreased in WS conditions the mean values of plant height $(\mathrm{PH})$, shoot biomass $(\mathrm{SB})$, root biomass (RB), total root length (TRL), root surface area (RSA) and root volume (RV) by 20.13, 38.53, 5.82, 13.41, 14.58 and $9.94 \%$, respectively, but increased those of root/ shoot ratio $(\mathrm{R} / \mathrm{S})$, root average diameter (RD), root length ratio (RLR), root surface area ratio (RSR), root

Table 1 Means value, standard deviation (SD) of traits under well-watered (WW) and water-stressed (WS) regimes and the drought-tolerant coefficient (DC) of each trait at vegetative growth stage

\begin{tabular}{llll}
\hline Traits & Mean \pm SD (WW) & Mean \pm SD (WS & Mean \pm SD (DC) \\
\hline PH $(\mathrm{cm})$ & $45.05 \pm 1.78$ & $35.98 \pm 1.93$ & $0.80 \pm 0.01 \mathrm{ef}$ \\
LAl & $3.11 \pm 0.44$ & $1.83 \pm 0.13$ & $0.59 \pm 0.05 \mathrm{f}$ \\
SB $\left(\mathbf{g ~ p l a n t ~}^{-1}\right)$ & $7.06 \pm 1.03$ & $4.34 \pm 0.25$ & $0.62 \pm 0.06 \mathrm{f}$ \\
RB $\left(\mathbf{g ~ p l a n t ~}^{-1}\right)$ & $1.89 \pm 0.18$ & $1.78 \pm 0.04$ & $0.95 \pm 0.07 \mathrm{de}$ \\
R/S & $0.28 \pm 0.02$ & $0.42 \pm 0.01$ & $1.53 \pm 0.04 \mathrm{~b}$ \\
TRL $(\mathrm{m})$ & $51.15 \pm 1.81$ & $44.29 \pm 2.37$ & $0.87 \pm 0.02 \mathrm{e}$ \\
RSA $\left(\mathrm{cm}^{2}\right)$ & $969.69 \pm 62.85$ & $828.29 \pm 61.42$ & $0.86 \pm 0.10 \mathrm{e}$ \\
RV $\left(\mathrm{cm}^{3}\right)$ & $14.69 \pm 0.83$ & $13.23 \pm 1.10$ & $0.91 \pm 0.12 \mathrm{e}$ \\
RD $\left(\mathrm{mm}^{2}\right)$ & $0.55 \pm 0.02$ & $0.63 \pm 0.04$ & $1.15 \pm 0.11 \mathrm{~cd}$ \\
RLR $(\mathrm{m} / \mathrm{g})$ & $5.91 \pm 0.55$ & $7.44 \pm 0.15$ & $1.38 \pm 0.19 \mathrm{c}$ \\
RSR $\left(\mathrm{cm}^{2} / \mathrm{g}\right)$ & $113.21 \pm 8.43$ & $138.67 \pm 8.38$ & $1.23 \pm 0.05 \mathrm{c}$ \\
RVR $\left(\mathrm{cm}^{3} / \mathrm{g}\right)$ & $1.75 \pm 0.35$ & $2.19 \pm 0.18$ & $1.29 \pm 0.36 \mathrm{bc}$ \\
RDR $(\mathrm{mm} / \mathrm{g})$ & $0.06 \pm 0.01$ & $0.11 \pm 0.01$ & $1.87 \pm 0.07 \mathrm{a}$ \\
RBR & $0.21 \pm 0.01$ & $0.29 \pm 0.01$ & $1.37 \pm 0.03 \mathrm{bc}$ \\
\hline
\end{tabular}

Means followed by the same letter within the third column are not significantly different $(p \leq 0.05)$ as determined by Duncan's multiple-range test $(n=3)$ volume ratio (RVR), root average diameter ratio (RDR), root biomass ratio (RBR) by $50.00,14.55,25.89,22.49$, $25.14,83.33$, and $38.09 \%$, respectively, as compared with the WW regime (Table 1). This indicated that the adverse effects of drought stress on shoots were greater than roots. Furthermore, there was significant difference between the DC of RDR and DC of other traits according to Duncan's multiple comparisons $(P<0.05)$.

\section{Assessing drought tolerance at the reproductive growth stage (Expt. 2)}

Phenotypic variation was confirmed by the average phenotypic value, SD and the DC of each trait when water was controlled at reproductive growth phase (RGP) (Table 2). The mean value of 8 traits decreased, while only one trait increased under water-stressed regime. Root biomass (RB) showed the largest drought coefficient (1.01) which increased by $2.22 \%$, demonstrating that this trait was the less impacted by drought conditions in this group of cultivars. The mean values of hundred seeds weight (HSW) and main stem node number (MSNN) were reduced in WS conditions by 0.16 and $4.83 \%$, respectively. And there was no significant difference between the drought-tolerant coefficient (DC) of the two and the DC of RB according to Duncan's multiple-range test, indicating that the three agronomic traits were less affected by soil moisture. Moreover, for these varieties, WS treatment decreased the mean values of plant height $(\mathrm{PH})$, pods per plant (PPP), seeds per plant (SPP), yield per plant (YPP), stem biomass (STB), pod biomass (PB) by 8.49, 19.09, 25.05\%, 24.24.80, 26.23, and $20.98 \%$, respectively, as compared with WW treatment.

Table 2 Means value, standard deviation (SD) of traits under well-watered (WW) and water-stressed (WS) regimes and the drought-tolerant coefficient (DC) of each trait at reproductive growth phase

\begin{tabular}{|c|c|c|c|}
\hline Traits & Mean \pm SD $(\mathrm{WW})$ & Mean \pm SD (WS) & Mean $\pm S D(D C)$ \\
\hline $\mathrm{PH}(\mathrm{cm})$ & $96.35 \pm 11.70$ & $88.81 \pm 9.40$ & $0.92 \pm 0.02 a b c$ \\
\hline MSNN & $15.54 \pm 1.31$ & $15.11 \pm 0.92$ & $0.97 \pm 0.02 a b$ \\
\hline PPP & $32.94 \pm 13.51$ & $27.66 \pm 6.00$ & $0.88 \pm 0.18 a b c$ \\
\hline SPP & $67.65 \pm 28.18$ & $54.10 \pm 18.41$ & $0.82 \pm 0.10 b c$ \\
\hline HSW (g) & $19.35 \pm 2.67$ & $19.32 \pm 2.18$ & $0.99 \pm 0.03 \mathrm{a}$ \\
\hline YPP (g plant ${ }^{-1}$ ) & $12.61 \pm 4.71$ & $10.15 \pm 3.24$ & $0.82 \pm 0.04 \mathrm{C}$ \\
\hline RB (g plant ${ }^{-1}$ ) & $3.61 \pm 0.58$ & $3.69 \pm 1.03$ & $1.01 \pm 0.12 \mathrm{a}$ \\
\hline STB (g plant ${ }^{-1}$ ) & $9.72 \pm 2.71$ & $7.70 \pm 1.97$ & $0.79 \pm 0.04 c$ \\
\hline PB (g plant ${ }^{-1}$ ) & $4.67 \pm 1.84$ & $3.86 \pm 1.29$ & $0.84 \pm 0.06 b c$ \\
\hline
\end{tabular}

Means followed by the same letter within the third column are not significantly different $(p \leq 0.05)$ as determined by Duncan's multiple-range test $(n=3)$ 


\section{Relationship of the same trait between WS and WW treatments}

Significant and positive correlations were observed between WS and WW regimes for the same traits including $\mathrm{PH}\left(r^{2}=0.819, P<0.01\right)$, LAI $\left(r^{2}=0.192, P<0.05\right)$, RB $\left(r^{2}=0.253, P<0.05\right)$, RSA $\left(r^{2}=0.494, P<0.01\right)$ and RSR $\left(r^{2}=0.435, P<0.01\right)$ when water was controlled at vegetative growth phase (Fig. 1), and thus the above five parameters could serve as reliable characters in drought screening. At reproductive growth stage, correlations between WW and WS regimes for the same indicators in all the investigated traits $\left(\mathrm{PH}, r^{2}=0.679, P<0.01\right.$; MSNN, $r^{2}=0.411, P<0.01 ;$ PPP $, r^{2}=0.344, P<0.01$; SPP, $r^{2}=0.288, P<0.05$; HSW, $r^{2}=0.543, P<0.01$; YPP, $r^{2}=0.493, P<0.01 ; \mathrm{RB}, r^{2}=0.745, P<0.01 ; \mathrm{STB}, r^{2}=$ $\left.0.525, P<0.01 ; \mathrm{PB}, r^{2}=0.238, P<0.05\right)$ were all significant (Fig. 2). At the whole growth stage, it was also found that the same indicators of all investigated agronomic traits $\left(\mathrm{PH}, r^{2}=0.681, P<0.01 ; \mathrm{FPH}, r^{2}=0.536, P<\right.$ 0.01; MSNN, $r^{2}=0.693, P<0.01$; BR, $r^{2}=0.514, P<0.01$ ) of Shenyang were positively correlated with those of Chaoyang (Fig. 3).

\section{Genetic variation and broad sense heritability of the investigated traits \\ Assessing drought tolerance at vegetative growth stage (Expt. 1)}

The ANOVA revealed that there were significant effects $(P<0.05)$ for 9 traits including plant height $(\mathrm{PH})$, leaf area index (LAI), shoot biomass (SB), root/shoot ratio $(\mathrm{R} / \mathrm{S})$, root surface area (RSA), root length ratio (RLR), root surface area ratio (RSR), root average diameter ratio (RDR), root biomass ratio (RBR) between two water regimes and 11 tested traits including PH, LAI, SB, total root length (TRL), root surface area (RSA), root volume $(\mathrm{RV})$, root average diameter (RD), root length ratio (RLR), root surface area ratio (RSR), root volume ratio
(RVR), root average diameter ratio (RDR) among 20 cultivars (Table 3). Only 5 traits (TRL, RV, RD, RVR, RDR) varied greatly $(P<0.05)$ between variety and water regime interactions. The genetic variation coefficient $(\mathrm{CVg})$ ranged from 16.49 to $38.95 \%$ on WW regime and from 15.32 to $41.62 \%$ on WS regime for the 14 traits, respectively (Table 3 ). The lowest broad sense heritability $\left(H^{2}\right)$ was estimated for R/S (0.34), suggesting that the soil moisture made a larger contribution to the variation of the trait. The higher $H^{2}$ estimates, in these traits were obtained for PH, LAI, RB, RSA and RSR with a significant linear relationship between WS and WW regimes (Fig. 1 and Table 3).

\section{Assessing drought tolerance at the reproductive growth stage (Expt. 2)}

Analysis of variance, genetic variation coefficient $(\mathrm{CVg})$ and broad sense heritability $\left(H^{2}\right)$ of each trait under WS and WW regimes at reproductive growth phase were given in Table 4. Extremely significant differences $(P<$ $0.01)$ in plant height $(\mathrm{PH})$, main stem node number (MSNN), pods per plant (PPP), seeds per plant (SPP), hundred seeds weight (HSW), yield per plant (YPP), root biomass (RB), stem biomass (STB), and pod biomass (PB) occurred between the tested varieties. The great differences were also observed in PH, MSNN, SPP, HSW, STB and PB between the interactions. The $C V g$ ranged from 13.29 to $47.99 \%$ under WW condition and from 12.87 to $50.30 \%$ under WS condition for 9 traits, respectively. The maximum and minimum broad sense heritability $\left(H^{2}\right)$ was estimated for $\mathrm{PH}(0.90)$ and $\mathrm{PB}$ (0.71), respectively. The $H^{2}$ values for the 9 investigated traits were all more than 0.71 , for instance, MSNN (0.81), SPP (0.73), etc. This indicated that the variations of the traits were mostly due to genetic differences and these traits were highly heritable.

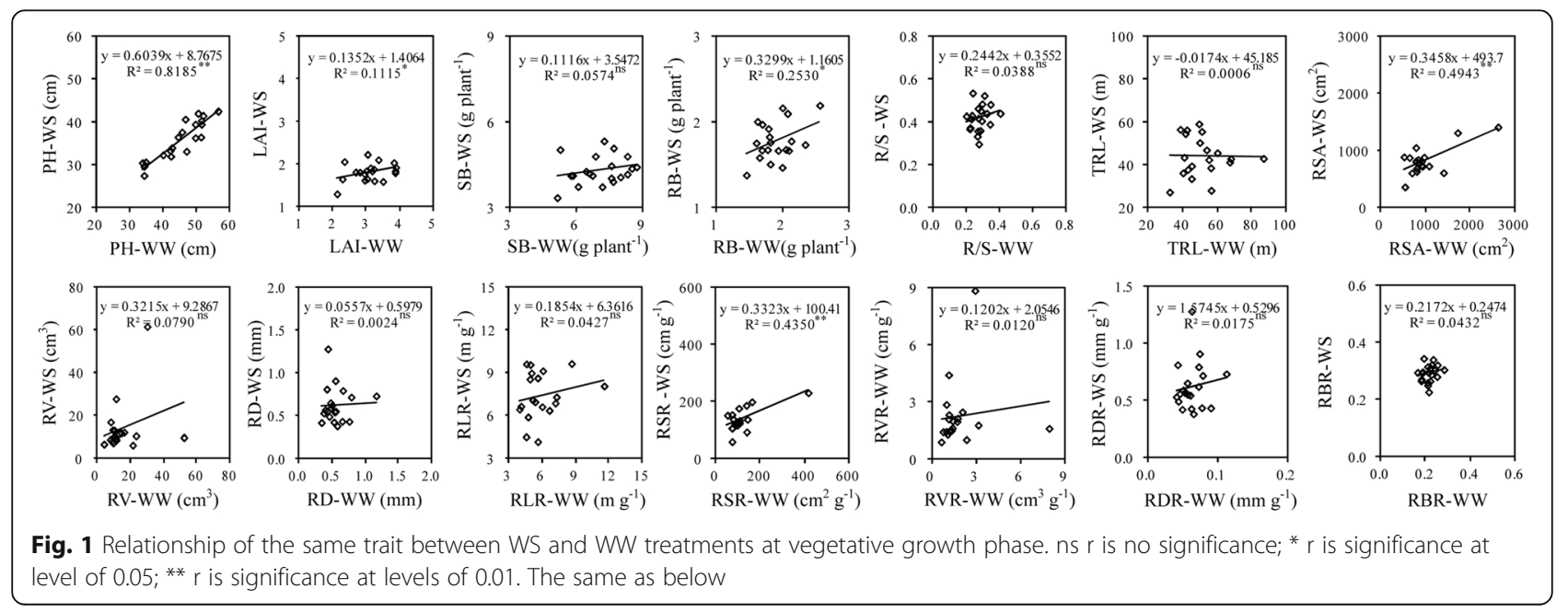



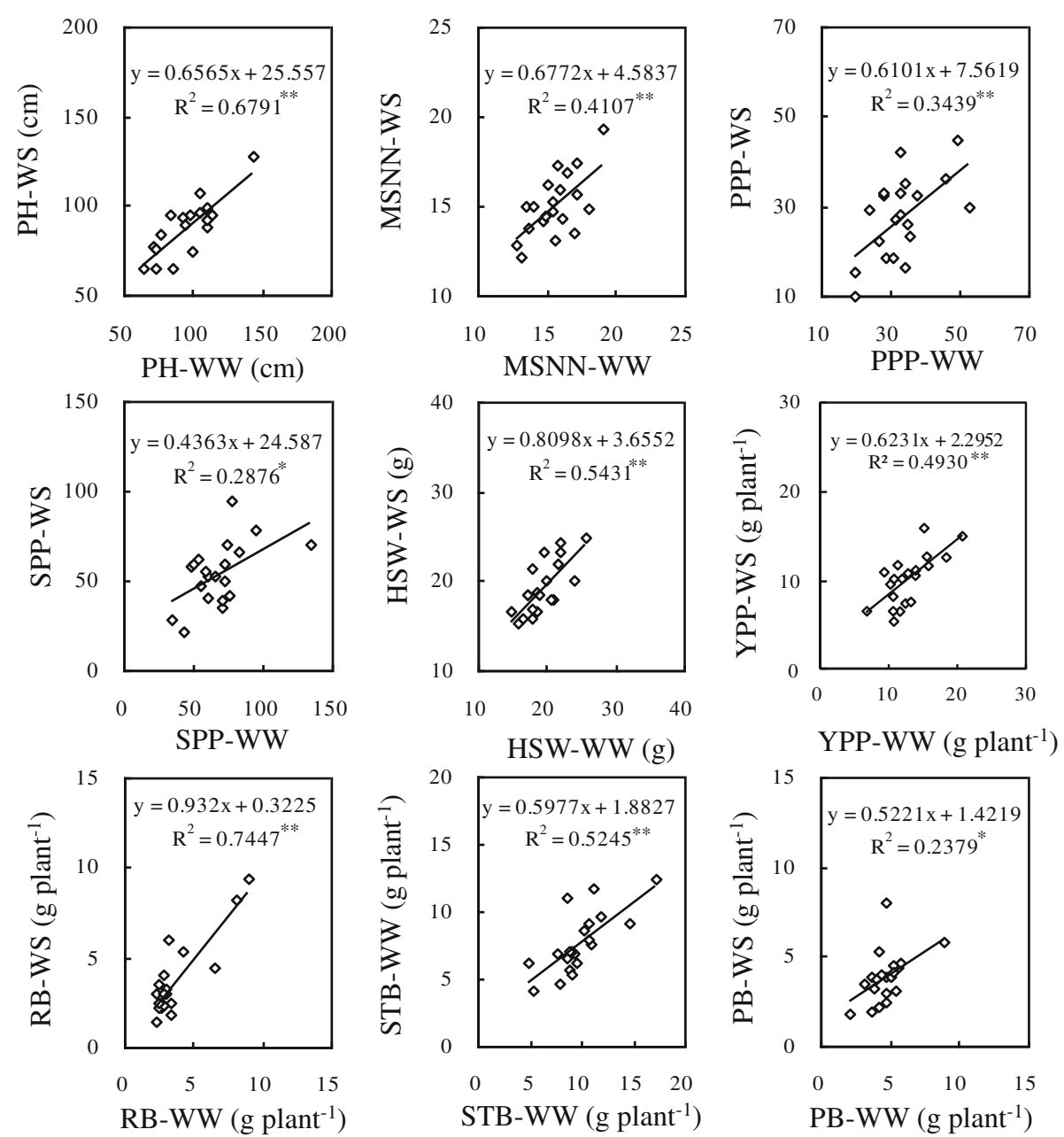

Fig. 2 Relationship of the same trait between WS and WW treatments at reproductive growth phase

Assessing drought tolerance at the whole growth stage (Expt. 3) Variety $(\mathrm{V})$, location (L) and $\mathrm{L} \times \mathrm{V}$ interactions had significant effects $(P \leq 0.05)$ for yield, plant height $(\mathrm{PH})$, first pod height $(\mathrm{FPH})$, branches (BR) in 2 years (Table 5). The main effects associated with variety and $\mathrm{L} \times \mathrm{V}$ interaction term were also significant $(P \leq 0.05)$ with respect to main stem node number (MSNN) in both years. However, location did not significantly affect MSNN in 2014, suggesting that MSNN was less affected by the different rainfall conditions. The $C V g$ for the 5 investigated traits ranged from 13.77 to $72.83 \%$ in Shenyang and from 15.72 to $88.00 \%$ in Chaoyang during 2014-2015, respectively (Table 5). In addition, $C V g$ values of 3 traits, i.e., yield, $\mathrm{PH}, \mathrm{MSNN}$ ranged between 10 and $30 \%$, and for first pod height $(\mathrm{FPH})$ and branches (BR), $C V g$ values were more than $30 \%$ in 2014-2015. Higher $H^{2}$ was observed for the five traits tested in the 2 years, indicating that the phenotypic variations of these traits in this group of genotypes were mostly due to genetic differences and they were highly heritable traits.
Identification and classification of drought tolerance among diverse genotypes

Assessing drought tolerance at vegetative growth stage and reproductive growth stage (Expts. 1 and 2)

The MFVD can be used as a comprehensive index to evaluate the drought tolerance of soybean genotypes according to the 14 characteristics during the vegetative growth period and the 9 traits for the reproductive growth period (Table 6). Among the 20 soybean accessions, 3 accessions (LD24, JD36 and TF31) showed drought tolerance (Level 2) when water was controlled at vegetative growth phase, 2 accessions (TD37 and LD26) showed highly drought tolerance (Level 1) water controlled at reproductive growth stage. Thus, these accessions could be used as resources for drought tolerance improvement in soybean breeding. Besides, 3 accessions (LD10, FD17 and LD21) and 1 accession (LD17) was screened for susceptible (Level 4) to water stress during vegetative growth phase and reproductive growth phase, respectively. 

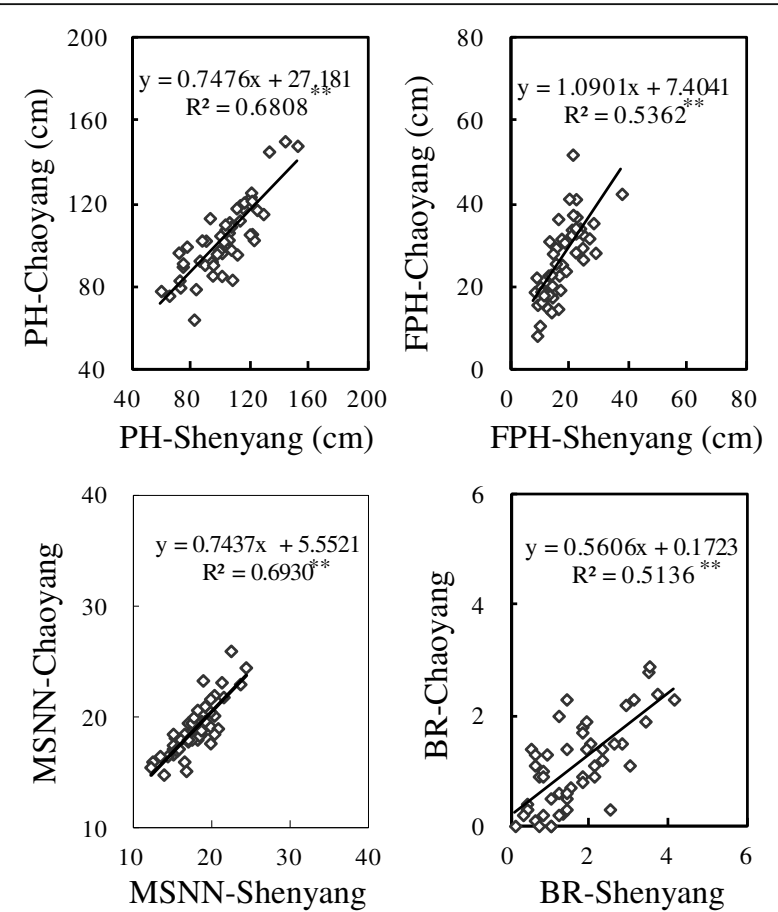

Fig. 3 Relationship of the same trait between well-watered condition (Shenyang) and water stress condition (Chaoyang)

Assessing drought tolerance at the whole growth stage (Expt. 3) Fifty soybean genotypes were classified into four groups based on relative drought index (RDI) of yield and yield in semi-arid region in the field experiments during the 2 years (Fig. 4 and Table 7). Group I was comprised of the drought tolerant and high yield genotypes with higher RDI values than average (0.93) of 50 genotypes and higher yield than the average $\left(2785.95 \mathrm{~kg} \mathrm{ha}^{-1}\right)$. This group had 23 cultivars including LD24, JD36 and TF31 that have been screened with drought tolerance at vegetative growth phase. The group II comprised of nondrought tolerant and high yield genotypes which produced more than average yield of 50 genotypes at semi-arid zone, but the response to drought stress was lower than the average. There were only 2 genotypes within group II. The group III involved drought tolerance and low yield cultivars produced higher than average soybean yield, but the resistance to drought stress was above the average. There were 7 cultivars in group III including TD37 and LD26 screened with highly drought tolerance when water was controlled at reproductive growth phase. The group IV consisted of non-drought tolerance and low yield accessions including 18 genotypes that showed lower yield and RDI values than the average.

\section{Correlation between MFVD and DC of each trait} Assessing drought tolerance at vegetative growth stage (Expt. 1) Correlation coefficients between the membership function value of drought tolerance (MFVD) and the drought-tolerant coefficient (DC) of each trait at vegetative growth stage were analyzed (Table 8). The $\mathrm{DC}_{\mathrm{RB}}$, $\mathrm{DC}_{\mathrm{R} / \mathrm{S}}, \mathrm{DC}_{\mathrm{RSA}}, \mathrm{DC}_{\mathrm{RLR}}, \mathrm{DC}_{\mathrm{RSR}}$ and $\mathrm{DC}_{\mathrm{RBR}}$ showed highly positive correlations with the MFVD (Table 8; $P<0.05$ ). Moreover, correlation coefficients between the DC of each trait and those of others were also analyzed and shown in Table 8. The highest correlation of DC was found between RBR and R/S $(r=1.00 ; P<0.01)$, meaning that $\mathrm{RBR}$ was closely related to $\mathrm{R} / \mathrm{S}$. In addition, $\mathrm{DC}_{\mathrm{PH}}$, $\mathrm{DC}_{\mathrm{LAI}}$ and $\mathrm{DC}_{\mathrm{SB}}$ were also positively correlated with each other. In contrast, a negative correlation occurred between $\mathrm{DC}_{\mathrm{R} / \mathrm{S}}$ and $\mathrm{DC}_{\mathrm{LAI}}, \mathrm{DC}_{\mathrm{SB}}$.

\section{Assessing drought tolerance at the reproductive growth stage (Expt. 2)}

Correlation coefficients between the MFVD and DC of each trait at reproductive growth stage were listed in Table 9. The great positive correlation occurred between

Table 3 Analysis of variance (ANOVA), genetic variation coefficient ( $\mathrm{CVg})$ and broad sense heritability $\left(H^{2}\right)$ of each trait on two water conditions of 20 varieties at vegetative growth phase

\begin{tabular}{|c|c|c|c|c|c|c|c|c|c|c|c|c|c|c|c|}
\hline \multirow{2}{*}{$\begin{array}{l}\text { Variation } \\
\text { Source }\end{array}$} & \multirow[t]{2}{*}{$d f$} & \multicolumn{14}{|c|}{ Means of squares } \\
\hline & & $\mathrm{PH}(\mathrm{cm})$ & $\mathrm{LAl}$ & SB & $\mathrm{RB}$ & $\mathrm{R} / \mathrm{S}$ & TRL & RSA & RV & $\mathrm{RD}$ & RLR & RSR & RVR & RDR & RBR \\
\hline $\begin{array}{l}\text { Replication } \\
\text { (R) }\end{array}$ & 2 & 138.04 & 3.11 & 16.09 & 0.47 & 0.01 & 638.84 & $80,066.06$ & 298.45 & 0.08 & 0.16 & 7099.86 & 6.40 & 0.00 & 0.00 \\
\hline Water (W) & 1 & $2470.67^{* * *}$ & $49.59^{*}$ & $223.29^{*}$ & 0.34 & $0.63^{* * *}$ & 1410.16 & $589,699.18^{*}$ & 18.64 & 0.17 & $77.34^{*}$ & $16,762.72^{*}$ & 6.77 & $0.05^{*}$ & $0.19^{* * *}$ \\
\hline Variety (V) & 19 & $186.08^{* * *}$ & $0.58^{* *}$ & $2.48^{* *}$ & 0.25 & 0.01 & $358.16^{* *}$ & $\begin{array}{l}\text { 657, } \\
814.55^{* * *}\end{array}$ & $500.60^{* * *}$ & $0.12^{* * *}$ & $10.28^{* *}$ & $\begin{array}{l}16 \\
765.40^{* * *}\end{array}$ & $9.18^{* * *}$ & $0.00^{* * *}$ & 0.00 \\
\hline $\mathbf{W} \times \mathbf{V}$ & 19 & 16.67 & 0.36 & 1.71 & 0.11 & 0.01 & $374.67^{* *}$ & $187,211.60$ & $282.48^{* *}$ & $0.11^{* * *}$ & 6.78 & 5149.34 & $7.38^{* * *}$ & $0.00^{* * *}$ & 0.00 \\
\hline Error & 38 & 12.09 & 0.26 & 1.13 & 0.15 & 0.01 & 157.98 & $112,709.22$ & 108.32 & 0.03 & 4.35 & 3403.59 & 2.51 & 0.00 & 0.00 \\
\hline$C V_{g}(\%)(W W)$ & & 16.49 & 25.51 & 23.06 & 23.30 & 27.66 & 27.69 & 30.36 & 38.95 & 36.08 & 34.84 & 38.24 & 38.77 & 34.08 & 21.04 \\
\hline$C V_{g}(\%)(\mathrm{WS})$ & & 15.32 & 21.31 & 22.00 & 20.92 & 23.32 & 27.75 & 30.74 & 38.08 & 37.02 & 31.89 & 32.29 & 41.62 & 39.82 & 16.36 \\
\hline$H^{2}$ & & 0.91 & 0.62 & 0.44 & 0.63 & 0.34 & 0.35 & 0.74 & 0.58 & 0.45 & 0.47 & 0.72 & 0.47 & 0.43 & 0.36 \\
\hline
\end{tabular}

******* Mean of squares significant at $p<0.05,0.01$, and 0.001 , respectively 
Table 4 ANOVA, $\mathrm{CVg}$ and $\mathrm{H}^{2}$ of each trait on two water conditions of 20 varieties at reproductive growth phase

\begin{tabular}{|c|c|c|c|c|c|c|c|c|c|c|}
\hline \multirow{2}{*}{$\begin{array}{l}\text { Variation } \\
\text { Source }\end{array}$} & \multirow[t]{2}{*}{ df } & \multicolumn{9}{|c|}{ Means of squares } \\
\hline & & $\mathrm{PH}(\mathrm{cm})$ & MSNN & PPP & SPP & HSW & YPP & $\mathrm{RB}$ & STB & PB \\
\hline Replication (R) & 2 & 4449.43 & 49.58 & 4184.43 & $21,640.29$ & 234.28 & 632.88 & 26.02 & 217.40 & 98.10 \\
\hline Water (W) & 1 & $1706.30^{*}$ & 5.63 & $837.41^{*}$ & $5504.69^{*}$ & 0.02 & $181.11^{*}$ & 0.19 & $123.54^{*}$ & $19.62^{*}$ \\
\hline Variety (V) & 19 & $1669.39^{* * *}$ & $14.17^{* * *}$ & $368.50^{* * *}$ & $1717.99^{* * *}$ & $41.92^{* * * *}$ & $46.92^{* * *}$ & $22.44^{* * *}$ & $32.44^{* * *}$ & $8.51^{* * *}$ \\
\hline $\mathbf{W} \times \mathbf{V}$ & 19 & $182.18^{* * *}$ & $3.11^{* * *}$ & 96.20 & $534.98^{*}$ & $6.44^{* *}$ & 8.37 & 1.68 & $5.48^{*}$ & $2.94^{* *}$ \\
\hline Error & 38 & 43.72 & 0.58 & 90.16 & 293.81 & 2.94 & 9.82 & 1.38 & 2.68 & 1.30 \\
\hline$C V_{g}(\%)(W W)$ & & 22.89 & 13.29 & 47.88 & 51.73 & 19.67 & 46.00 & 16.06 & 38.62 & 47.99 \\
\hline$C V_{g}(\%)(W S)$ & & 20.10 & 12.87 & 47.71 & 47.04 & 18.63 & 42.93 & 27.93 & 39.34 & 50.30 \\
\hline$H^{2}$ & & 0.90 & 0.81 & 0.74 & 0.73 & 0.86 & 0.82 & 0.88 & 0.84 & 0.71 \\
\hline
\end{tabular}

******* Mean of squares significant at $p<0.05,0.01$, and 0.001 , respectively

MFVD and $\mathrm{DC}_{\mathrm{SPP}}(r=0.47 ; P<0.05), \mathrm{DC}_{\mathrm{YPP}}(r=0.42$; $P<0.05), \mathrm{DC}_{\mathrm{PB}}(r=0.41 ; P<0.05)$ and $\mathrm{DC}_{\mathrm{RB}}(r=0.46$; $P<0.05)$. Besides, correlation coefficients between the DC of each trait were available in Table 9 when water was controlled at reproductive growth stage. Significant positive correlations of $\mathrm{DC}$ of tested traits were observed between $\mathrm{DC}_{\mathrm{YPP}}$ and $\mathrm{DC}_{\mathrm{PH}}, \mathrm{DC}_{\mathrm{YPP}}$ and $\mathrm{DC}_{\mathrm{MSNN}}, \mathrm{DC}_{\mathrm{YPP}}$ and $\mathrm{DC}_{\mathrm{PPP}}, \mathrm{DC}_{\mathrm{YPP}}$ and $\mathrm{DC}_{\mathrm{SPP}}, \mathrm{DC}_{\mathrm{YPP}}$ and $\mathrm{DC}_{\mathrm{STB}}$, and $\mathrm{DC}_{\mathrm{YPP}}$ and $\mathrm{DC}_{\mathrm{PB}}$, revealing that these traits were closely related to yield per plant in soybean. The significant correlations also occurred between $\mathrm{DC}_{\mathrm{PH}}$ and $\mathrm{DC}_{\mathrm{MSNN}}(r=$ $0.63 ; P<0.01), \mathrm{DC}_{\mathrm{PPP}}$ and $\mathrm{DC}_{\mathrm{SPP}}(r=0.96 ; P<0.01)$, $\mathrm{DC}_{\mathrm{PPP}}$ and $\mathrm{DC}_{\mathrm{PB}}(r=0.91 ; P<0.01)$ (Table 9).

\section{Drought tolerance explained by multiple DC of traits Assessing drought tolerance at vegetative growth stage (Expt. 1)}

Multiple linear stepwise regression to explain the MFVD prediction with the accepted 4 limiting DC of traits at vegetative growth phase were estimated and listed in Table 10. The results showed that the MFVD variation was explained $36.60,21.00,10.20$, and $5.90 \%$ by DC of
R/S, TRL, LAI and RSR, respectively. As a result, 73.70\% of the variation in MFVD was caused by these DC of 4 traits. Regression coefficient, standard error, $T$-value and probability of the 4 accepted variables at vegetative growth phase were calculated and displayed in Table 11. The prediction equation for MFVD with accepted $4 \mathrm{lim}$ iting DC of traits was as:

$$
\begin{aligned}
Y_{M F V D V}= & 0.279-0.176 A 1+0.110 A 2+0.082 A 3 \\
& +0.024 A 4
\end{aligned}
$$

where $Y_{M F V D V}$ was the membership functions value of drought tolerance for one cultivar at VGP, $A 1, A 2, A 3$ and $A 4$ were the $\mathrm{DC}$ value for $\mathrm{R} / \mathrm{S}$, TRL, LAI and RSR, respectively.

\section{Assessing drought tolerance at reproductive growth stage (Expt. 2)}

Multiple linear stepwise regression to explain the MFVD prediction with the accepted $6 \mathrm{DC}$ of traits at reproductive growth phase were estimated and listed in Table 10 . The results showed that the MFVD variation was

Table 5 ANOVA, CVg and $H^{2}$ of each trait under well-watered condition (Shenyang) and water stress condition (Chaoyang) of 50

\begin{tabular}{|c|c|c|c|c|c|c|c|c|c|c|c|}
\hline \multirow{3}{*}{$\begin{array}{l}\text { Variation } \\
\text { Source }\end{array}$} & \multirow[t]{3}{*}{$\mathrm{df}$} & \multicolumn{10}{|c|}{ Means of squares } \\
\hline & & \multicolumn{5}{|l|}{2014} & \multicolumn{5}{|l|}{2015} \\
\hline & & Yield (kg ha-1) & $\mathrm{PH}(\mathrm{cm})$ & $\mathrm{FPH}(\mathrm{cm})$ & MSNN & $B R$ & Yield $\left(\mathrm{kg} \mathrm{ha}^{-1}\right)$ & $\mathrm{PH}(\mathrm{cm})$ & $\mathrm{FPH}(\mathrm{cm})$ & MSNN & $\mathrm{BR}$ \\
\hline Replication (R) & 2 & $94,924.81$ & 181.05 & 47.54 & 5.29 & 0.36 & 1646.295 & 161.05 & 141.67 & 0.06 & 0.07 \\
\hline Location (L) & 1 & $8,300,616.00^{*}$ & $4901.29^{*}$ & $4434.42^{*}$ & 103.57 & $6.57^{*}$ & $9372584^{*}$ & $1889.55^{*}$ & $7868.95^{*}$ & $44.96^{*}$ & $47.88^{*}$ \\
\hline Variety (V) & 49 & $880,734.50^{* * *}$ & $1979.29^{* * *}$ & $414.44^{* * *}$ & $42.99^{* * *}$ & $4.53^{* * *}$ & $46.92^{* * *}$ & $2170.80^{* * *}$ & $293.17^{* * *}$ & $32.11^{* * *}$ & $6.07^{* * *}$ \\
\hline$L \times V$ & 49 & $269,710.70^{* * *}$ & $235.37^{* * *}$ & $116.45^{* * *}$ & $5.51^{* * *}$ & $0.97^{* * *}$ & $1,287,688.00^{* * *}$ & $451.74^{* * *}$ & $93.81^{* * *}$ & $6.07^{* * *}$ & $1.64^{* * *}$ \\
\hline Error & 96 & $94,624.68$ & 10.14 & 7.05 & 1.58 & 0.27 & $318,273.50$ & 7.52 & 7.95 & 0.66 & 0.22 \\
\hline \multicolumn{2}{|c|}{$C V_{g}(\%)$ (Shenyang) } & 13.77 & 20.54 & 43.09 & 18.07 & 72.52 & 19.95 & 16.06 & 41.48 & 15.73 & 72.83 \\
\hline \multicolumn{2}{|c|}{$C V_{g}(\%)$ (Chaoyang) } & 21.32 & 15.72 & 43.11 & 14.28 & 88.00 & 22.65 & 27.93 & 36.19 & 12.69 & 83.64 \\
\hline \multicolumn{2}{|c|}{$H^{2}$} & 0.74 & 0.89 & 0.78 & 0.88 & 0.81 & 0.83 & 0.93 & 0.75 & 0.84 & 0.78 \\
\hline
\end{tabular}
varieties in both years

***,*** Mean of squares significant at $p<0.05,0.01$, and 0.001 , respectively 
Table 6 Subordinate function values and class to drought resistance on genotypes tested when water was controlled at vegetative growth phase and reproductive growth phase

\begin{tabular}{lllllllllllllllllllllll}
\hline $\begin{array}{l}\text { Cultivar } \\
\text { Name }\end{array}$ & LD10 & LD15 & LD17 & LD18 & LD21 & LD23 & LD24 & LD26 & JD36 & JD37 & KY11 & KY12 & TF29 & TF31 & TD37 & TD40 & TD49 & DD12 & SN10 & FD17 \\
\hline $\begin{array}{l}\text { MFVD } \\
\text { of VGP }\end{array}$ & 0.33 & 0.36 & 0.47 & 0.40 & 0.33 & 0.37 & 0.52 & 0.38 & 0.53 & 0.43 & 0.39 & 0.41 & 0.40 & 0.49 & 0.37 & 0.45 & 0.40 & 0.35 & 0.41 & 0.33 \\
Level & 4 & 3 & 3 & 3 & 4 & 3 & 2 & 3 & 2 & 3 & 3 & 3 & 3 & 2 & 3 & 3 & 3 & 3 & 3 & 4 \\
$\begin{array}{l}\text { MFVD } \\
\text { of RGP }\end{array}$ & 0.48 & 0.51 & 0.43 & 0.55 & 0.52 & 0.51 & 0.45 & 0.61 & 0.53 & 0.49 & 0.54 & 0.47 & 0.51 & 0.44 & 0.61 & 0.45 & 0.49 & 0.53 & 0.52 & 0.53 \\
Level & 3 & 3 & 4 & 3 & 3 & 3 & 3 & 1 & 3 & 3 & 3 & 3 & 3 & 3 & 1 & 3 & 3 & 3 & 3 & 3 \\
\hline
\end{tabular}

explained $44.60,20.10,11.60,6.60,6.70$, and $4.70 \%$ by DC of SPP, YPP, PH, PB, MSNN and STB, respectively. In total, $94.30 \%$ of the variation in MFVD was ascribed to these 6 DC of traits. Regression coefficients for the 6 accepted variables were calculated and shown in Table 11. The prediction equation for MFVD with $6 \mathrm{lim}$ iting DC of traits was as:

$$
\begin{aligned}
Y_{M F V D R}= & -0.421+0.165 B 1+0.108 B 2+0.048 B 3 \\
& +0.060 B 4+0.174 B 5+0.130 B 6
\end{aligned}
$$

where $Y_{M F V D R}$ was the membership functions value of drought tolerance for one cultivar at RGP, $B 1, B 2, B 3$, $B 4, B 5$ and $B 6$ were the DC value for SPP, YPP, PH, PB, MSNN and STB, respectively.

\section{Discussion}

Soybean is one of the major and wide spread crops in the world and is rather sensitive to water stress. Many drought-tolerant varieties have been developed for other crops [17, 20,34, 35]. However, study on a set of accurate, stable, simple and systematic method and index system for identification and selection of drought tolerance in soybean is still limited. It is an important step to improve the identification of soybean drought-tolerant

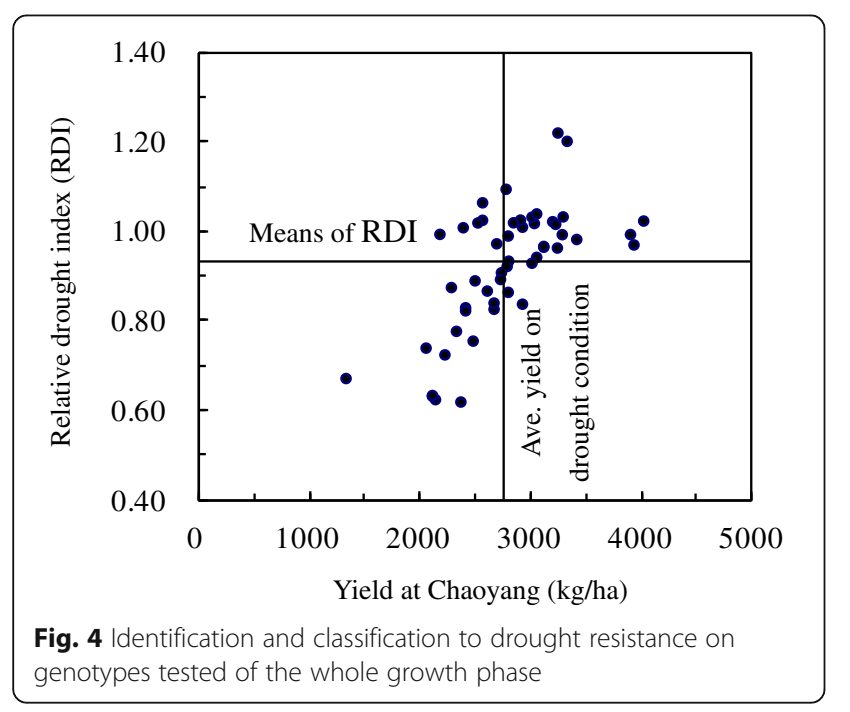

germplasm by screening a number of key and stable traits with high heritability for the identification of drought tolerance in soybean.

Drought stress caused reductions in plant height, pods per plant, 100-kernel weight, yield per plant, LAI, biological yield, root length, root volume, etc. [4, 36-39]. Soybean yield is mainly a function of number of plants, dry matter production, seed numbers and seed size. Water stress have been reported to reduce seed weight, total biomass, pods per plant, seeds per plant, seeds per pod, 100-grain weight, and ultimately caused a decline in soybean yield [40-42]. In this study, some drought traits measured among 20 soybean accessions under WS regimes also showed remarkable decline in $\mathrm{PH}, \mathrm{LAI}, \mathrm{SB}$, $\mathrm{RB}, \mathrm{TRL}, \mathrm{RSA}, \mathrm{RD}$ and RV water controlled at vegetative growth phase. In addition, decline in PH, PPP, SPP, YPP, STB and PB was observed when water was controlled at reproductive growth phase. In contrast, striking increase occurred in R/S, RD, RLR, RSR, RVR, RDR and RBR under water stress condition, as compared with the well water treatment. This showed that drought stress enhanced the proportion of root distribution throughout the plant $[43,44]$.

The present study from Expt.2 and Expt.3 also showed that all the investigated agronomic traits in the WW treatments were positively correlated with those of the WS treatment. The similar results were obtained by Liu et al. [45]. However, in Expt.1 of this study, only the five traits, i.e., PH, LAI, SB, RSA and RSR had high and positive correlations $(P<0.05)$ between WW and WS conditions. This could be attributed to the previous experimental conditions where water stress was weaker than the present study. In addition, the differences in the tested crops and the measured indicators were also the main reason.

The significant differences in variety and water stress were observed on plant height, LAI, shoot biomass, root biomass, R/S, total root length, etc. [46-49]. The ANOVA analysis in Expt.1 also indicated that there were significant differences for some traits including PH, LAI, SB, RSA, RLR, RSR, etc. between among 20 cultivars and two water regimes. The genetic variation for the trait under selection and a higher heritability of the trait are 
Table 7 Identification and classification to drought resistance on genotypes tested of the whole growth stage

\begin{tabular}{llll}
\hline Drought tolerance and high yield & $\begin{array}{l}\text { Non-drought tolerance } \\
\text { and high yield }\end{array}$ & Drought tolerance and low yield & Non-drought tolerance and low yield \\
\hline DD14, JD36, JD37, LD18, LD24, LD25, & LX2, & DD11, KY11, LD17, LD23, LD26, & DD12, DD13, DD15, FD17, KY12, L08-28, \\
LD29, LD30, SN12, SN16, SN17, TF31, & TD47. & LD31, TD37. & LD15, LD21, LD22, LD28, SN8, SN10, SN11, \\
TD39, TD43, TD45, TD46, TD48, TD49, & & & TD38, TD40, TD42, XY11, YW6. \\
TD50, TD55, TD56, TD57, YW9. & & \\
\hline
\end{tabular}

necessary for breeding and the trait utility within the selection process [23]. In Expt.1, higher heritability found in PH, RSA, RSR, LAI and RB indicated that the five traits were highly heritable, and strong positive correlation was observed among the five parameters under normal and drought conditions. There were significant differences in plant height, main stem node number, yield, and internode length in soybean between cultivars [1]. The Expt. 2 demonstrated that the significant differences were found for indicators such as $\mathrm{PH}, \mathrm{MSNN}$, PPP, SPP, HSW, YPP, RB, STB, and PB between variety treatments, and all these indicators presented higher $H^{2}$ values. Therefore, the 9 secondary characteristics could be considered as criteria for drought resistance assessment.

Previous research has conclusively indicated positive correlations between MFVD and the drought-tolerant coefficient of some traits including plant height, grain number per spike, biological yield per plant, grain yield per plant, thousand kernel weight in wheat [23], which is also supported by our results; the conclusion stated clearly that MFVD was significantly positively correlated with the $\mathrm{DC}_{\mathrm{RB}}, \mathrm{DC}_{\mathrm{R} / \mathrm{S}}, \mathrm{DC}_{\mathrm{RSA}}, \mathrm{DC}_{\mathrm{RSR}}$ and $\mathrm{DC}_{\mathrm{RBR}}$ during vegetative growth period and $\mathrm{DC}_{\mathrm{YPP}}, \mathrm{DC}_{\mathrm{RB}}$, and $\mathrm{DC}$ during reproductive growth period. It is therefore concluded that the less the values of these traits decreased under drought stress, the more drought-tolerant the genotypes were. In addition, the DC of some traits were positively correlated with each other such as $\mathrm{DC}_{\mathrm{PH}}$ and $\mathrm{DC}_{\mathrm{LAI}}, \mathrm{DC}_{\mathrm{PH}}$ and $\mathrm{DC}_{\mathrm{SB}}, \mathrm{DC}_{\mathrm{TRL}}$ and $\mathrm{DC}_{\mathrm{RSA}}, \mathrm{DC}_{\mathrm{PH}}$ and $\mathrm{DC}_{\mathrm{MSNN}}, \mathrm{DC}_{\mathrm{MSNN}}$ and $\mathrm{DC}_{\mathrm{PPP}}, \mathrm{DC}_{\mathrm{YPP}}$ and $\mathrm{DC}_{\mathrm{SPP}}$. As compared with different drought criteria, we revealed that root-related indicators had relatively higher correlation with drought tolerance of plant than other ones tested, thus we regarded the root system as more valuable standard for evaluating the drought resistance of soybean. Similar studies have also pointed out the important role of roots in enhancing plant resistance to drought stress [50-52].

The drought resistance is a complex characteristic. A single characteristic cannot reflect the complex traits of the drought resistance mechanism, so more traits should be considered to evaluate the drought resistance in soybean. Stepwise multiple linear regression analyses revealed that the drought-tolerant coefficient of R/S, TRL, LAI and RSR could explain $73.70 \%$ of the total variation in MFVD at VGP, but higher heritability only found in LAI and RSR indicated that the 2 traits could serve as reliable indicators in drought evaluation. This again showed that the root system plays an important role in

Table 8 Correlation coefficients between the membership function value of drought tolerance (MFVD) and the drought-tolerant coefficient (DC) of each trait at vegetative growth stage

\begin{tabular}{|c|c|c|c|c|c|c|c|c|c|c|c|c|c|c|}
\hline & MFVD & $D C_{P H}$ & $D C_{L A l}$ & $\mathrm{DC}_{\mathrm{SB}}$ & $\mathrm{DC}_{\mathrm{RB}}$ & $D C_{R / S}$ & $D C_{T R L}$ & $D C_{\text {RSA }}$ & $\mathrm{DC}_{\mathrm{RV}}$ & $D C_{R D}$ & $D C_{R L R}$ & $D C_{R S R}$ & $\mathrm{DC}_{\mathrm{RVR}}$ & $D C_{R D R}$ \\
\hline$\overline{D C_{P H}}$ & -0.14 & & & & & & & & & & & & & \\
\hline$D C_{\text {LAI }}$ & -0.22 & $0.75^{* *}$ & & & & & & & & & & & & \\
\hline $\mathrm{DC}_{\mathrm{SB}}$ & -0.10 & $0.83^{* *}$ & $0.89^{* *}$ & & & & & & & & & & & \\
\hline$D C_{R B}$ & $0.47^{*}$ & 0.31 & 0.24 & 0.18 & & & & & & & & & & \\
\hline$D C_{R / S}$ & $0.66^{* *}$ & -0.40 & $-0.49^{*}$ & $-0.63^{* *}$ & $0.62^{* *}$ & & & & & & & & & \\
\hline$D C_{T R L}$ & 0.40 & 0.35 & 0.11 & 0.15 & 0.41 & 0.21 & & & & & & & & \\
\hline$D C_{R S A}$ & $0.52^{*}$ & 0.14 & -0.03 & -0.10 & 0.38 & 0.43 & $0.56^{* *}$ & & & & & & & \\
\hline$D C_{R V}$ & -0.35 & -0.10 & -0.03 & 0.05 & -0.06 & -0.42 & -0.08 & -0.14 & & & & & & \\
\hline$D C_{R D}$ & 0.17 & 0.28 & 0.23 & 0.23 & $0.48^{*}$ & 0.21 & 0.07 & 0.17 & 0.10 & & & & & \\
\hline$D C_{R L R}$ & $0.47^{*}$ & 0.00 & -0.28 & -0.28 & 0.19 & 0.40 & $0.87^{* *}$ & $0.65^{* *}$ & -0.07 & -0.08 & & & & \\
\hline$D C_{R S R}$ & $0.53^{*}$ & -0.14 & -0.32 & -0.41 & 0.22 & $0.56^{* *}$ & $0.48^{*}$ & $0.93^{* *}$ & -0.10 & 0.13 & $0.73^{* *}$ & & & \\
\hline$D C_{R V R}$ & -0.26 & -0.29 & -0.24 & -0.20 & -0.13 & -0.28 & -0.15 & -0.16 & $0.94^{* *}$ & -0.11 & -0.01 & -0.42 & & \\
\hline$D C_{R D R}$ & 0.25 & -0.01 & -0.05 & -0.09 & 0.35 & 0.39 & -0.04 & 0.27 & -0.13 & $0.92^{* *}$ & 0.00 & 0.34 & -0.16 & \\
\hline$D C_{R B R}$ & $0.65^{* *}$ & $-0.45^{*}$ & $-0.52^{*}$ & $-0.67^{* *}$ & $0.59^{* *}$ & $1.00^{* *}$ & 0.19 & $0.43^{*}$ & -0.13 & 0.21 & 0.41 & $0.58^{* *}$ & -0.27 & 0.40 \\
\hline
\end{tabular}

${ }^{*} \mathrm{r}$ is significance at level of $0.05 ;{ }^{* *} \mathrm{r}$ is significance at level of $0.01 ;{ }^{* * *} \mathrm{r}$ is significance at level of 0.001 
Table 9 Correlation coefficients between the MFVD and the DC of each trait at reproductive growth stage

\begin{tabular}{|c|c|c|c|c|c|c|c|c|c|}
\hline & MFVD & $D C_{P H}$ & $\mathrm{DC}_{\text {MSNN }}$ & $D C_{p p P}$ & $D C_{S P P}$ & $\mathrm{DC}_{\mathrm{HSW}}$ & $D C_{Y P P}$ & $D C_{R B}$ & $\mathrm{DC}_{\mathrm{STB}}$ \\
\hline$D C_{P H}$ & 0.22 & & & & & & & & \\
\hline$D C_{\text {MSNN }}$ & 0.05 & $0.63^{* *}$ & & & & & & & \\
\hline$D C_{P P P}$ & 0.03 & $0.49^{*}$ & $0.57^{* *}$ & & & & & & \\
\hline$D C_{S P P}$ & $0.47^{*}$ & $0.55^{* *}$ & $0.61^{* *}$ & $0.96^{* *}$ & & & & & \\
\hline $\mathrm{DC}_{\mathrm{HSW}}$ & 0.15 & -0.38 & -0.28 & $-0.64^{* *}$ & $-0.62^{* *}$ & & & & \\
\hline$D C_{Y P P}$ & $0.42^{*}$ & $0.56^{* *}$ & $0.61^{* *}$ & $0.84^{* *}$ & $0.93^{* *}$ & -0.36 & & & \\
\hline$D C_{R B}$ & $0.46^{*}$ & -0.09 & 0.00 & -0.15 & -0.19 & -0.25 & -0.32 & & \\
\hline$D C_{S T B}$ & 0.21 & $0.66^{* *}$ & 0.33 & $0.47^{*}$ & $0.56^{* *}$ & $-0.49^{*}$ & $0.50^{*}$ & 0.05 & \\
\hline$D C_{P B}$ & $0.41^{*}$ & $0.44^{*}$ & $0.51^{*}$ & $0.91^{* *}$ & $0.87^{* *}$ & $-0.53^{*}$ & $0.84^{* *}$ & -0.15 & $0.43^{*}$ \\
\hline
\end{tabular}

${ }^{*} \mathrm{r}$ is significance at level of $0.05 ;{ }^{*} \mathrm{r}$ is significance at level of $0.01 ;{ }^{* *} \mathrm{r}$ is significance at level of 0.001

improving the drought resistance. Root traits contribute to drought avoidance of plants, which is relevant to avoid agricultural drought and sustain crop performance [53]. When soil moisture is insufficient, root traits are also essential for maintaining crop yields [54]. Many scientists have also claimed that modifying the root system structure will enhance crop yields and achieve a new green revolution $[55,56]$. In addition, stepwise multiple linear regression analyses illustrated that the DC of SPP, YPP, PH, PB, MSNN and STB could explain 94.30\% of the variation in MFVD at RGP. As a result, those six traits could be used as a combination to screen soybean genotypes for drought resistance.

\section{Conclusions}

Even though drought-tolerant indices have many advantages, it is more and more widely used in combination with the value of membership function to screen drought resistant varieties in many crops. The present

Table 10 Multiple linear stepwise regression to explain the MFVD with DC of each trait at vegetative growth phase and reproductive growth phase

\begin{tabular}{|c|c|c|c|c|c|}
\hline Variables & Step & Variable entered & Partial $R^{2}$ & Model $R^{2}$ & Sig. \\
\hline \multirow{4}{*}{$\begin{array}{l}\text { MFVD } \\
\text { (VGP) }\end{array}$} & 1 & $D C_{R / S}(A 1)$ & 0.366 & 0.366 & **** \\
\hline & 2 & $D C_{\text {TRL }}(\mathrm{A} 2)$ & 0.210 & 0.776 & * \\
\hline & 3 & DC LAI $(A 3)$ & 0.102 & 0.838 & $* *$ \\
\hline & 4 & $D C_{\text {RBR }}(\mathrm{A} 4)$ & 0.059 & 0.868 & * \\
\hline \multirow{6}{*}{$\begin{array}{l}\text { MFVD } \\
\text { (RGP) }\end{array}$} & 1 & $\mathrm{DC}_{\mathrm{SPP}}(\mathrm{B} 1)$ & 0.446 & 0.902 & $* * *$ \\
\hline & 2 & DC $C_{Y P P}(B 2)$ & 0.201 & 0.999 & $* *$ \\
\hline & 3 & $D C_{P H}(B 3)$ & 0.116 & 0.902 & $* * *$ \\
\hline & 4 & $D C_{P B}(B 4)$ & 0.066 & 0.953 & * \\
\hline & 5 & $\mathrm{DC}_{\text {MSNN }}(\mathrm{B} 5)$ & 0.067 & 0.987 & $* * *$ \\
\hline & 6 & DC $C_{\text {STB }}(\mathrm{B} 6)$ & 0.047 & 0.969 & * \\
\hline
\end{tabular}

MFVD (VGP) The membership function value of drought tolerance of vegetative growth phase, MFVD (RGP) The membership function value of drought tolerance of reproductive growth phase ${ }^{*}, * * * *$ Significant at $\mathrm{p}<$ $0.05,0.01$, and 0.001 , respectively investigation was carried out to identify drought tolerance genotypes integrated the two methods which is needed for the development of soybean varieties in the arid and semi-arid areas. As a result, 3 accessions (LD24, JD36 and TF31) with drought tolerant during vegetative growth phase and 2 cultivars (TD37 and LD26) with highly drought resistant at reproductive growth stage were screened according to MFVD under WS and WW conditions, respectively. Meanwhile, based on DC and yield in the semi-arid zone, 50 genotypes were classified as drought tolerance and high yield (DD14, JD36, JD37, LD18, LD24, LD25, LD29, LD30, SN12, SN16, SN17, TF31, TD39, TD43, TD45, TD46, TD48, TD49, TD50, TD55, TD56, TD57, YW9), non-drought tolerance and high yield (LX2, TD47), drought tolerance and low yield (DD11, KY11, LD17, LD23, LD26, LD31, TD37), and non-drought tolerance and low yield (DD12, DD13,

Table 11 Regression coefficient, standard error, T-value and probability of the accepted DC of each trait that can be used to predict the MFVD based on the stepwise regression analysis at vegetative growth phase and reproductive growth phase

\begin{tabular}{|c|c|c|c|c|c|}
\hline Variables & Variable entered & $\begin{array}{l}\text { Regression } \\
\text { coefficients }\end{array}$ & $\begin{array}{l}\text { Standard } \\
\text { error }\end{array}$ & $T$ & Sig. \\
\hline \multirow{5}{*}{$\begin{array}{l}\text { MFVD } \\
\text { (VGP) }\end{array}$} & Constant & 0.280 & 0.054 & 5.150 & $* * *$ \\
\hline & $D C_{R / S}(A 1)$ & -0.176 & 0.059 & -2.960 & * \\
\hline & $D C_{\text {TRL }}(A 2)$ & 0.110 & 0.020 & 5.400 & $* * *$ \\
\hline & $\mathrm{DC}_{\mathrm{LAI}}(\mathrm{A} 3)$ & 0.082 & 0.019 & 4.310 & $* * *$ \\
\hline & $D C_{R B R}(A 4)$ & -0.024 & 0.014 & -1.770 & * \\
\hline \multirow{7}{*}{$\begin{array}{l}\text { MFVD } \\
\text { (RGP) }\end{array}$} & Constant & -0.421 & 0.014 & -30.890 & $* * *$ \\
\hline & $D C_{S P P}(B 1)$ & 0.165 & 0.008 & 21.390 & $* * *$ \\
\hline & $D C_{Y P P}(B 2)$ & 0.108 & 0.006 & 18.650 & $* * *$ \\
\hline & $D C_{P H}(B 3)$ & 0.048 & 0.005 & 9.800 & $* * *$ \\
\hline & $D C_{P B}(B 4)$ & 0.060 & 0.004 & 13.670 & $* * *$ \\
\hline & $\mathrm{DC}_{\text {MSNN }}(B 5)$ & 0.174 & 0.009 & 18.560 & *** \\
\hline & $\mathrm{DC}_{\mathrm{STB}}(\mathrm{B} 6)$ & 0.130 & 0.004 & 30.500 & \\
\hline
\end{tabular}

***,*** Significant at $p<0.05,0.01$, and 0.001 , respectively 
DD15, FD17, KY12, L08-28, LD15, LD21, LD22, LD28, SN8, SN10, SN11, TD38, TD40, TD42, XY11, YW6). In comparison WS, WW treatment increased the mean values of 7 characteristics but decreased that of the others at vegetative growth stage, and increased that of 8 traits but only decreased that of 1 trait at reproductive growth stage for 20 varieties. Correlation analysis showed that the MFVD was significantly and positively correlated with $\mathrm{DC}_{\mathrm{RB}}, \mathrm{DC}_{\mathrm{R} / \mathrm{S}}, \mathrm{DC}_{\mathrm{RSA}}, \mathrm{DC}_{\mathrm{RLR}}, \mathrm{DC}_{\mathrm{RSR}}$ and $D_{R B R}$ of vegetative growth phase and $D_{Y P P}$ and $D C_{R B}$ of reproductive growth stage. The results from ANOVA analysis showed that there were significant differences $(P<0.05)$ for 9 traits (PH, LAI, SB, R/S, RSA, RLR, RSR, RDR, RBR) between two water regimes, for 11 tested indicators (PH, LAI, SB, TRL, RSA, RV, RD, RLR, RSR, RVR, RDR) among 20 cultivars, for 5 properties (TRL, $R V, R D, R V R, R D R$ ) between the interactions when water was controlled at vegetative growth stage. While there was significant difference $(P<0.05)$ for only one trait $(\mathrm{PH})$ between two water regimes, for all 9 investigated features (PH, MSNN, PPP, SPP, HSW, YPP, RB, $\mathrm{STB}, \mathrm{PB}$ ) among 20 cultivars, and for 5 indices (PH, MSNN, SPP, HSW, STB, STB) between the interactions when water was controlled at reproductive growth phase. The $H^{2}$ for the investigated traits was estimated by genetic variance and phenotypic variance in two water treatments. However, the $H^{2}$ of only one trait $(\mathrm{PH})$ was higher than 0.9 and that of two traits (RSA, RSR) were more than 0.7 during vegetative growth stage, while that of the 9 investigated traits were all more than 0.7 during reproductive growth stage. This indicated that the variations of these traits were mostly due to genetic differences and they were highly heritable traits. There was a significant and positive linear relationship between WS and WW condition for the five traits (PH, LAI, SB, RSA and RSR) at vegetative growth stage and for all the agronomic traits at reproductive growth stage and the whole growth stage.

\section{Methods}

\section{The pot experiments}

A total of 20 soybean varieties from Liaoning Academy of Agricultural Science and Tieling Academy of Agricultural Science were selected in the present study to determine their drought tolerance properties at the vegetative growth stage (Expt. 1) and the reproductive growth stage (Expt. 2) under water stress conditions. The origin and description of 20 soybean varieties are shown in Table 12. The controlled experiments were conducted in a greenhouse of Liaoning Academy of Agricultural Science in Shenyang, Liaoning, China $\left(41^{\circ} 49^{\prime} \mathrm{N}, 123^{\circ} 32^{\prime}\right.$ W). For both experiment seeds were sowed in plastic pots $(28 \mathrm{~cm}$ average diameter and $28 \mathrm{~cm}$ average tall) contained $15 \mathrm{~kg}$ air dry brown soil from 0 to $20 \mathrm{~cm}$ plough layer. Soil samples were collected before planting to analyze the characteristics shown in Table 13. Six soybean seeds were sown in each pot and the population was thinned to two plants per pot when the first trifoliate leaf emerged. The pots were arranged in the electric movable greenhouse which was opened in the sunny day to maintain living conditions in a natural environment and closed in the rainy days to avoid the rain soaking plastic basin.

Two series of pot experiments were arranged in two factors randomized complete block design with three replicates. The water treatments included well-watered (WW) and water-stressed (WS) regimes. The soil water content of WW regime was maintained at field capacity, and that of WS regime was $50 \%$ of the field capacity. Twenty domestic soybean genotypes used in the experiments. Two pots for each genotype with two water regimes were grown next to each other in pairs. For each pair the treatments were randomly assigned to each pot. The soil water content and field capacity were determined before the experiment, and then calculate the weight of pot and soil for each water treatment (plant weight is ignored). The pots were weighed every $2 \mathrm{~d}$ to maintain soil moisture at the target weight by rewatering.

\section{Expt. 1}

Water-stressed (WS) was applied 30 days when the plants had three fully expanded leaves and ended at flowering phase. Thereafter, plants were harvested and a total of 14 traits were investigated and calculated. Definition of traits and their description of measurement are listed in Table 14.

\section{Expt. 2}

Water-stressed (WS) was applied 50 days at the beginning of flowering R1 until the first physiological maturity pod appearance R7. After all plants maturity, plants were harvested and a total of 9 traits were investigated which are listed in Table 14.

\section{Expt. 3 (field studies)}

Fifty soybean genotypes from Liaoning Academy of Agricultural Science and Tieling Academy of Agricultural Science including 18 varieties in Expts. 1 and 2 were evaluated for drought tolerance in Chaoyang $\left(41^{\circ} 30^{\prime} \mathrm{N}, 120^{\circ} 29^{\prime} \mathrm{W}, 170 \mathrm{~m}\right.$ a.s.l.) located in the semiarid zone and Shenyang $\left(41^{\circ} 82^{\prime} \mathrm{N}, 123^{\circ} 55^{\prime} \mathrm{W}, 52.9 \mathrm{~m}\right.$ a.s.l.) located at humid and sub-humid region, representing different rainfall characteristics in 2014-2015. Both Chaoyang and Shenyang are temperate continental monsoon climate type with severe and dry winter, and high temperature and concentrated rainfall in summer. The annual average sunshine, the mean temperature, and 
Table 12 The origin and description of 20 soybean studies varieties

\begin{tabular}{|c|c|c|}
\hline Cultivar Name & Origin & Description \\
\hline LD10 & Shenyang, China & Commercial cultivar (LD3 × L82-5185) \\
\hline LD15 & Shenyang, China & Commercial cultivar (L85062× ZCY18) \\
\hline LD17 & Shenyang, China & Commercial cultivar (LD3 × L92-2738 M) \\
\hline LD18 & Shenyang, China & Commercial cultivar (L89094× L93040) \\
\hline LD21 & Shenyang, China & Commercial cultivar (L8878× L93009) \\
\hline LD23 & Shenyang, China & Commercial cultivar (LD10×L91086) \\
\hline LD24 & Shenyang, China & Commercial cultivar (LD3 × YPZ) \\
\hline LD26 & Shenyang, China & Commercial cultivar (L8880 × IOA22) \\
\hline JD36 & Jinzhou, China & Commercial cultivar (JD2×TF18) \\
\hline JD37 & Jinzhou, China & Commercial cultivar (MC25 × L9825) \\
\hline KY11 & Kaiyuan, China & Commercial cultivar (KJ7528× GZM) \\
\hline KY12 & Kaiyuan, China & Commercial cultivar (K8525 × KJ8157) \\
\hline TF29 & Tieling, China & Commercial cultivar $(8114$ × 84059) \\
\hline TF31 & Tieling, China & Commercial cultivar (LD3× Resnick) \\
\hline TD37 & Tieling, China & Commercial cultivar (89034-10×TF29) \\
\hline TD40 & Tieling, China & Commercial cultivar $(89078 \times 92035)$ \\
\hline TD49 & Tieling, China & Commercial cultivar (93058-19×TF29) \\
\hline DD12 & Dandong, China & Commercial cultivar (D806 × LD10) \\
\hline SN10 & Shenyang, China & Commercial cultivar (SN92-16 × SN91-44) \\
\hline FD17 & Fushun, China & Commercial cultivar (F82-47× DJ1) \\
\hline
\end{tabular}

frost free days in a normal year in Chaoyang are around $2900 \mathrm{~h}, 6^{\circ} \mathrm{C}$ and $135 \mathrm{~d}$, respectively, and those in Shenyang are around $2400 \mathrm{~h}, 8^{\circ} \mathrm{C}$ and $150 \mathrm{~d}$, respectively.

The field experiment was arranged in complete block design replicated three times with two locations (Shenyang representing well-watered condition is located in a humid and semi-humid area; Chaoyang representing water stress condition is located in a semi-arid area). Both Chaoyang and Shenyang, 50 genotypes were sown in field plots, and each plot consisted of four $6 \mathrm{~m}$ rows, in East-West orientation, with $0.60 \mathrm{~m}$ inter-row spacing. Plots were over-seeded with hand planters and seedlings thinned to a final stand of 166,700 plants $\mathrm{ha}^{-1}$. The plots were fertilized with $45-70-60 \mathrm{~kg} \mathrm{ha}^{-1}$ in the form of $\mathrm{N}-\mathrm{P}_{2} \mathrm{O}_{5}-\mathrm{K}_{2} \mathrm{O}$ before planting. The soil samples of two locations were typically brown soil that was taken before planting to analyze the characteristics given in Table 13.
After maturity, an area of $6.0 \mathrm{~m}^{2}$ was harvested by hand from the two central rows from each plot. The whole harvested area was used to determine yield. Five plants from the second row were harvested and a total of 4 traits were investigated which were listed in Table 14.

\section{Estimation of drought-tolerant coefficient (DC) and membership function value of drought tolerance (MFVD)}

The drought tolerance coefficient (DC) is calculated according to the following equation: data ratio derived from the WS and WW regimes of the same genotype for each trait $[23,57,58]$.

$$
D C_{i j r}=T_{i j w s r} / T_{i j w w r} D C_{i j}=\frac{1}{r} \sum_{i j=1}^{r} D C_{i j r}
$$

Table 13 Some initial properties of the soils in each experiment

\begin{tabular}{llllllllll}
\hline Experiment number & Location & $\mathrm{pH}$ & $\begin{array}{l}\mathrm{OM} \\
(\%)\end{array}$ & Total $\mathrm{N}(\%)$ & $\begin{array}{l}\text { Total } \\
\mathrm{P}(\%)\end{array}$ & $\begin{array}{l}\text { Total } \\
\mathrm{K}(\%)\end{array}$ & $\begin{array}{l}\text { Avai.N } \\
\left(\mathrm{mg} \mathrm{kg}^{-1}\right)\end{array}$ & $\begin{array}{l}\text { Avai.P } \\
\left(\mathrm{mg} \mathrm{kg}^{-1}\right)\end{array}$ & $\begin{array}{l}\text { Avai.K } \\
\left(\mathrm{mg} \mathrm{kg}^{-1}\right)\end{array}$ \\
\hline Expts. 1, 2 & Shenyang & 6.90 & 1.18 & 0.12 & 0.08 & 2.42 & 100 & 16.8 & 98 \\
Expt. 3 & Shenyang & 6.60 & 2.68 & 0.12 & 0.18 & 2.64 & 100 & 25.4 & 135 \\
$(2014)$ & Chaoyang & 6.90 & 2.12 & 0.11 & 0.16 & 2.78 & 94.0 & 22.8 & 164 \\
Expt. 3 & Shenyang & 6.60 & 2.58 & 0.13 & 0.17 & 2.58 & 110 & 24.8 & 148 \\
(2015) & Chaoyang & 6.90 & 2.24 & 0.11 & 0.17 & 2.75 & 102 & 23.4 & 175 \\
\hline
\end{tabular}


Table 14 Trait name and description of their measurement and calculation

\begin{tabular}{|c|c|}
\hline $\begin{array}{l}\text { Experiment } \\
\text { No. }\end{array}$ & Trait names and description of their measurement and calculation \\
\hline Expt. 1 & 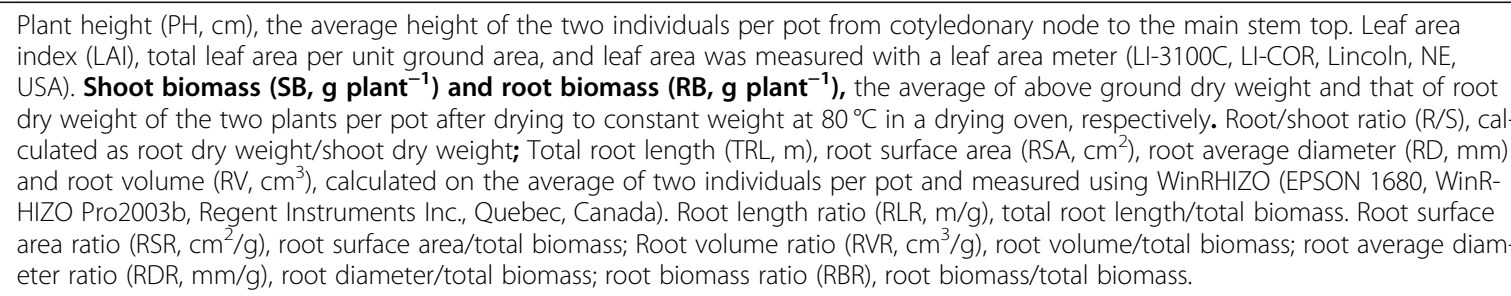 \\
\hline Expt. 2 & $\begin{array}{l}\text { Plant height (PH, cm), the average height of the two individuals per pot from cotyledonary node to the main stem top. Main stem } \\
\text { node number (MSNN), Pods per plant (PPP) and Seeds per plant (SPP), measured on the average of } 2 \text { plants in the pot at maturity; } \\
\text { Hundred seeds weight (HSW, g), calculated the weight of } 100 \text { seeds; Yield per plant (YPP, g plant }{ }^{-1} \text { ), the average yield of the two } \\
\text { individuals per pot. Root biomass (RB, g plant } \mathbf{~ p l a s ~}^{-1} \text { ), Stem biomass (STB, g plant }{ }^{-1} \text { ) and Pod biomass (PB, g plant }{ }^{-1} \text { ), measured on the } \\
\text { average of } 2 \text { plants which were separated into bean, root, stem and pod determined after drying, respectively. }\end{array}$ \\
\hline Expt. 3 & $\begin{array}{l}\text { Plant height }(\mathrm{PH}, \mathrm{cm}) \text {, First pod height }(\mathrm{FPH}, \mathrm{cm}) \text {, Main stem node number (MSNN) and Branches (BR), were estimated in } 5 \text { plants per } \\
\text { plot. }\end{array}$ \\
\hline
\end{tabular}

where $D C_{i j r}$ is the drought-tolerant coefficient of the $j$-th trait for the $i$-th cultivar in the $r$-th replication; $T_{i j w s r}$ and $T_{i j w w r}$ are the value of the $j$-th trait for the $i$-th cultivar evaluated under WS and WW treatments in the $r$-th replication, respectively; $D C_{i j}$ is the average value of drought-tolerant coefficient of $j$-th trait for the $i$-th cultivar.

Soybean drought tolerance was also evaluated by the membership function value. This methodology gives a comprehensive assessment by using the membership functions based on the theory of fuzzy mathematics. The membership function of a fuzzy set is a generalization of the indicator function in classical sets; it represents the degree of truth as an extension of valuation [59]. For any set $T$, a membership function on $T$ is any function from $T$ to the real unit interval $[0,1]$. According to the DC, the modified MFVD was calculated following the equations:

$$
F_{i j}=\frac{D C_{i j}-D C_{j \min }}{D C_{j \max }-D C_{j \min }} \quad F_{i}=\frac{1}{n} \sum_{j=1}^{n} F_{i j}
$$

where $F_{i j}$ is the membership function value of the $j$-th trait for $i$-th cultivar for drought tolerance; $D C_{\text {jmax }}$ and $D C_{j m i n}$ were the maximum value and minimum value of the drought resistant coefficient for the $j$-th trait, respectively; $F_{i}$ is the average value of the membership function of measured traits for the $i$-th cultivar for drought tolerance.

Drought tolerance is divided into five levels according to the average value $\left(\overline{F_{i}}\right)$ and standard deviation $(S D)$ of MFVD in two series of pot experiments. Class and level to drought resistance are listed in Table 15.

Evaluation and classification of drought tolerance of soybean genotypes at the whole growth stage based on yield relative drought index (RDI) and yield in semi-arid areas in the field experiment. RDI of yield was calculated as [60]:

$$
R D I=\frac{Y_{i w s}}{Y_{i w w}} \div \frac{Y_{m w s}}{Y_{m w w}}
$$

where $Y_{i w s}$ and $Y_{i w w}$ were the yield of tested $i$-th genotype and $Y_{m w s}$ and $Y_{m w s}$ were the mean yield of all genotypes under water-stressed (semi-arid region) and wellwatered (humid and sub-humid region) conditions, respectively.

\section{Data analysis}

Multiple linear regression was performed with SAS 8.0 statistical software to construct the select indices of MFVD using multiple DC of some traits. Analysis of variance (ANOVA), correlation and heritability $\left(H^{2}\right)$ analyses were carried out for all the data sets using SPSS 16.0 statistical software, and significance differences was determined at the significances of $0.05,0.01,0.001$ probability level using the Duncan's tests.

Variation was partitioned into relevant sources of variation to test for differences among genotypes. The linear model was used as follows:

$$
Y_{r k i}=\mu+R_{r}+W_{k}++G_{i}+W G_{k i}+\varepsilon_{r k i}
$$

Table 15 Class and level to drought resistance of soybean genotypes according to the $\bar{F}_{i}$ and SD of MFVD

\begin{tabular}{lll}
\hline Level & $F_{i}$ & Class \\
\hline $\mathbf{1}$ & $F_{i} \geq \overline{F_{i}}+1.64 S D$ & Highly drought tolerant \\
2 & $\overline{F_{i}}+1.64 S D>F_{i} \geq \overline{F_{i}}+S D$ & Drought tolerant \\
$\mathbf{3}$ & $\overline{F_{i}}+S D>F_{i} \geq \overline{F_{i}}-S D$, & Moderate drought tolerant \\
$\mathbf{4}$ & $\overline{F_{i}}-S D>F_{i} \geq \overline{F_{i}}-1.64 S D$ & Susceptible \\
5 & $F_{i}<\overline{F_{i}}-1.64 S D$ & Highly susceptible \\
\hline
\end{tabular}


where $Y_{r k i}$ : observation corresponding to $k t h$ level of water factor, the ith level of genotypic factor and the $r t h$ replication; $\mu$ : general mean; $R_{r}$ : the $r t h$ replication effect; $W_{k}$ : the $k t h$ level of water treatment effect; $G_{i}$ : the ith genotypic treatment effect; $W G_{k i}$ i interaction between the $i t h$ level of genotypic treatment and the kth level of water treatment; and $\varepsilon_{r k i}$ : the residual error.

The genetic variation coefficient $\left(C V_{\mathrm{g}}\right)$ of each trait was calculated following the equation:

$$
C V_{g}=\frac{S D}{\bar{X}} \times 100 \%
$$

where $S D$ is standard deviation, $\bar{X}$ is the average value of the trait under the same water-controlled conditions.

The broad sense heritability $\left(H^{2}\right)$ of each trait was calculated following the equation:

$$
H^{2}=\frac{V_{g}}{V_{g}+V_{w g}+V_{e}}
$$

Where $V_{\mathrm{g}}$ is genotypic variance, $V_{w g}$ is the interaction variance between genotype and water treatment, $V_{e}$ is error variance.

\begin{abstract}
Abbreviations
WS: Water-stressed; WW: Well-watered; MFVD: Membership function value of drought tolerance; DC: Drought-tolerant coefficient; VGP: Vegetative growth phase; RGP: Reproductive growth phase; $H^{2}$ : Broad sense heritability; OM: Organic matter; Avai.: Available; N: Nitrogen; P: Phosphorus; K: Potassium; $\mathrm{DC}_{\mathrm{PH}}$ : Drought-tolerant coefficient of plant height; $D_{L A \mid}$ : Drought-tolerant coefficient of leaf area index; $D C_{S B}$ : Drought-tolerant coefficient of shoot biomass; $\mathrm{DC}_{\mathrm{RB}}$ : Drought-tolerant coefficient of root biomass; $\mathrm{DC}_{\mathrm{R} / \mathrm{s}}$ : Drought-tolerant coefficient of root/shoot ratio; $\mathrm{DC}_{\text {TRL: }}$ : Drought-tolerant coefficient of total root length; $\mathrm{DC}_{\mathrm{RSA}}$ : Droughttolerant coefficient of root surface area; $D C_{R V}$ : Drought-tolerant coefficient of root volume; $\mathrm{DC}_{\mathrm{RD}}$ : Drought-tolerant coefficient of root average diameter: $\mathrm{DC}_{\mathrm{RLR}}$ : Drought-tolerant coefficient of root length ratio; $D C_{\mathrm{RSR}}$ : Droughttolerant coefficient of root surface area ratio; $\mathrm{DC}_{\text {RvR: }}$ : Drought-tolerant coefficient of root volume ratio; $\mathrm{DC}_{\mathrm{RDR}}$ : Drought-tolerant coefficient of root average diameter ratio; $\mathrm{DC}_{\mathrm{RBR}}$ : Drought-tolerant coefficient of root biomass ratio; $\mathrm{DC}_{\text {MSNN }}$ : Drought-tolerant coefficient of main stem node number; DC spp: Drought-tolerant coefficient of seeds per plant; DCppp: Droughttolerant coefficient of pods per plant; DC $C_{\text {HSw: }}$ : Drought-tolerant coefficient of hundred seeds weight; DC STB: Drought-tolerant coefficient of stem biomass; $D C_{P B}$ : Drought-tolerant coefficient of pod biomass; $C_{Y p p}$ : Drought-tolerant coefficient of yield per plant
\end{abstract}

\section{Acknowledgements}

We thank Chuang Wang, Jiahong Wang and Yulu Yuan for their help with field and laboratory work.

\section{Authors' contributions}

$C Y$ and $W W$ designed the experiments. SS, CW, XS and SL carried out the experiments. FW analyzed experimental results. $\mathrm{CY}$ drafted the manuscript. $\mathrm{HL}$ revised it. All authors contributed to and approved the final manuscript.

\section{Funding}

The authors would like to thank the financial support from the National Key R\&D Plan Project (No. 2016YFD0100201-01), National Agriculture Ministry of China (No. CARS-004-CES11), National Science and Technology Ministry of China (No.2016ZX08004-005), Natural Science Foundation of Liaoning Province (2020-MS-047), and Liaoning Provincial Central Leading Local Development Project (2019JH6/10400001).

\section{Availability of data and materials}

All datasets generated or analyzed during this study are available from the corresponding author on reasonable request.

Ethics approval and consent to participate

Not applicable.

\section{Consent for publication}

Not applicable.

\section{Competing interests}

The authors declare that they have no competing interests.

\section{Author details}

${ }^{1}$ Crop Institute, Liaoning Academy of Agricultural Science, Shenyang 110161, Liaoning, China. ${ }^{2}$ School of Agriculture, Jilin University of Agricultural Science \& Technology, Jilin 132101, China. Institute of Agro-environmental Protection, MOA, Tianjin 300191, China.

Received: 20 February 2020 Accepted: 24 June 2020

Published online: 08 July 2020

\section{References}

1. Liu K. Soybeans: chemistry, technology, and utilization. Gaithersburg: Aspen Publishers; 1997. p. 1-22.

2. Shaheen T, Rahman M, Riaz MS, Zafar Y, Rahman M. 8-soybean production and drought stress. Abiotic Biotic Stress Soybean Production. 2016;1:177-96.

3. Sinclair T, Marrou H, Soltani A, Vadez V, Chandolu KC. Soybean production potential in Africa. Global Food Sec. 2014;3(1):31-40.

4. Ohashi Y, Nakayama N, Saneoka H, Fujita K. Effects of drought stress on photosynthetic gas exchange, chlorophyll fluorescence and stem diameter of soybean plants. Biol Plant. 2006;50(1):138-41.

5. Tang $Y$, Sun $X$, Wen $T$, Liu M, Yang $M$, Chen $X$. Implications of terminal oxidase function in regulation of salicylic acid on soybean seedling photosynthetic performance under water stress. Plant Physiol Biochem. 2017;112:19-28

6. Porcel R, Ruiz-Lozano JM. Arbuscular mycorrhizal influence on leaf water potential, solute accumulation, and oxidative stress in soybean plants subjected to drought stress. J Exp Bot. 2004;55:1743-50.

7. Du Y, Zhao Q, Chen L, Yao X, Zhang W, Zhang B, Xie F. Effect of drought stress on sugar metabolism in leaves and roots of soybean seedlings. Plant Physiol Biochem. 2020;146:1-12.

8. Cui Y, Jiang S, Jin J, Ning S, Feng P. Quantitative assessment of soybean drought loss sensitivity at different growth stages based on S-shaped damage curve. Agric Water Manag. 2019;213:821-32.

9. Specht JE, Hume DJ, Kumudini SV. Soybean yield potential-a genetic and physiological perspective. Crop Sci. 1999;39:1560-70.

10. Dogan E, Kirnak H, Copur O. Deficit irrigations during soybean reproductive stages and CROPGRO-soybean simulations under semi-arid climatic conditions. Field Crop Res. 2007;103(2):154-9.

11. Meckel L, Egli DB, Phillips RE, Radcliffe D, Leggett JE. Effect of moisture stress on seed growth in soybeans. Agron J. 1984;75:1027-31.

12. Hall AE. Is dehydration tolerance relevant to genotypic differences in leaf senescence and crop adaptation to dry environments? In: Close TJ, Bray EA, editors. Plant responses to cellular dehydration during environmental stress. California: Academic; 1993. p. 1-10.

13. Kumar A, Bernier J, Verulkar S, Lafitte HR, Atlin GN. Breeding for drought tolerance: direct selection for yield, response to selection and use of drought-tolerant donors in upland and lowland-adapted populations. Field Crop Res. 2008;107(3):221-31.

14. Adebayo MA, Menkir A. Assessment of hybrids of drought tolerant maize (Zea mays L.) inbred lines for grain yield and other traits under stress managed conditions. Nigerian J Genet. 2014;28(2):19-23.

15. Seymen M, Yavuz D, Dursun A, Kurtar ES, Türkmen Ö. Identification of drought-tolerant pumpkin (Cucurbita pepo L.) genotypes associated with certain fruit characteristics, seed yield, and quality. Agric Water Manag. 2019; 221:150-9.

16. Silva MA, Jifon JL, Sharma V, Silva JAG, Caputo MM, Damaj MB, Guimarães ER, Ferro MIT. Use of physiological parameters in screening drought tolerance in sugarcane genotypes. Sugar Technol. 2011;13:191-7. 
17. Gunes A, Inal A, Adak MS, Bagci EG, Cicek N, Eraslan F. Effect of drought stress implemented at pre- or post-anthesis stage on some physiological parameters as screening criteria in chickpea cultivars. Russ J Plant Physiol. 2008:55:59-67.

18. Fischer KS, Edmeades GO, Johnson EC. Selection for improvement in maize yield under moisture deficits. Field Crop Res. 1989;22:227-43.

19. Regan BP, Cress WA, Staden J. Van root growth, water relations, abscisic acid and proline level of drought resistant and drought sensitive maize cultivars in response to water stress. S Afr Bot. 1993;59(1):98-104.

20. Classen MM, Shaw RH. Water deficit effects on corn: II. Grain components. Agron J. 1970;62:652-5

21. Yan M, Huang W, Hu J, Lv Z, Lei S, Huang C. Evaluation of rice drought resistance by subordinate function. Hybrid Rice. 2009;24(5):76-9.

22. Peng Y, Shi G, Cui H. Evaluation of drought resistant of different processing tomato at seed germination stage under PEG-6000 stress. Seed. 2013;32(7): 44-9.

23. Chen X, Min D, Yasir TA, Hu YG. Evaluation of 14 morphological, yieldrelated and physiological traits as indicators of drought tolerance in Chinese winter bread wheat revealed by analysis of the membership function value of drought tolerance (MFVD). Field Crop Res. 2012;137:195-201.

24. Meng QL, Guan ZB, Feng BL, Chai Y, Hu YG. Principal component analysis and fuzzy clustering on drought-tolerance related traits of foxtail millet (Setaria italica). Sci Agric Sin. 2009;42(8):2667-75.

25. He XY, Wen RL, Wu CR, Zhou JG. Analysis of maize drought resistance at seeding stage by fuzzy subordination method. Southwest China J Agric Sci. 2008;21(1):52-6.

26. Song Q, Liu C, Bachir DG, Chen L, Hu Y. Drought resistance of new synthetic hexaploid wheat accessions evaluated by multiple traits and antioxidant enzyme activity. Field Crop Res. 2017;210:91-103.

27. Sadeghipour O, Abbasi S. Soybean response to drought and seed inoculation. World Appl Sci J. 2012;17(1):55-60.

28. Jha PK, Kumar SN, Inesa AVM. Responses of soybean to water stress and supplemental irrigation in upper indo-Gangetic plain: field experiment and modeling approach. Field Crop Res. 2018;219(15):76-86.

29. Shi G, Xia S, Ye J, Huang Y, Liu C, Zhang Z. PEG-simulated drought stress decreases cadmium accumulation in castor bean by altering root morphology. Environ Exp Bot. 2015;111:127-34.

30. Kashiwagi J, Krishnamurthy L, Purushothaman R, Upadhyaya HD, Gaur PM, Gowda CLL, Ito O, Varshney RK. Scope for improvement of yield under drought through the root traits in chickpea (Cicer arietinum L.). Field Crop Res. 2015;170:47-54.

31. Wright GC, Rao RCN. Peanut water relations. In: Smartt J, editor. The peanut crop. London: Chapman \& Hall; 1994. p. 281-325.

32. Matsui $T$, Singh BB. Root characteristics in cowpea related to drought tolerance at the seedling stage. Exp Agric. 2003;39:29-38.

33. Taiz L, Zeiger E. Stress physiology. In: Taiz L, Zeiger E, editors. Plant physiology. Sunderland: Academic; 2006. p. 671-81.

34. Sadras VO, Lake L, Leonforteb A, McMurray LS, Paull JG. Screening field pea for adaptation to water and heat stress: associations between yield, crop growth rate and seed abortion. Field Crop Res. 2013;150:60-70.

35. Torres RO, McNally KL, Cruz CV, Serraj R, Henry A. Screening of rice genebank germplasm for yield and selection of new drought tolerance donors. Field Crop Res. 2013;147:12-22.

36. Mejia MN, Madramootoo CA, Broughton RS. Influence of water table management on corn and soybean yields. Agric Water Manag. 2000;46(1): 73-89.

37. Rosadi RAB, Afandi, Senge M, Ito K, Adomako JT. Critical water content and water stress coefficient of soybean (Glycine max L. Merr.) under deficit irrigation. Paddy Water Environ. 2005;3(4):219-23.

38. Baghbani AA, Modarres-Sanavy SAM, Mashhadi-Akbar-Boojar M, AliMokhtassi-Bidgoli. Towards improving the agronomic performance, chlorophyll fluorescence parameters and pigments in fenugreek using zeolite and vermicompost under deficit water stress. Ind Crop Prod. 2017; 109:346-57.

39. Hosseini F, Mosaddeghi MR, Dexter AR. Effect of the fungus Piriformospora indica on physiological characteristics and root morphology of wheat under combined drought and mechanical stresses. Plant Physiol Biochem. 2017; 118:107-20.

40. Harris DS, Schapaugh WT, Kanemasu ET. Genetic diversity in soybean for leaf canopy temperature and yield. Crop Sci. 1984;24:839-42.
41. Jumrani K, Bhatia VS. Impact of combined stress of high temperature and water deficit on growth and seed yield of soybean. Physiol Mol Biol Plants. 2018;24:37-50.

42. Sammons DJ, Peters DB, Hymowitz T. Screening soybeans for tolerance to moisture stress: a field procedure. Field Crop Res. 1980;3:321-35.

43. Onillon B, Durand JL, Gastal F, Tournebize R. Drought effects on growth and carbon partitioning in a tall fescue sward grown at different rates of nitrogen fertilization. Eur J Agron. 1995;4(1):91-9.

44. Purushothaman R, Krishnamurthy L, Upadhyaya HD, Vadez V, Varshney RK. Root traits confer grain yield advantages under terminal drought in chickpea (Cicer arietinum L.). Field Crop Res. 2017;201:146-61.

45. Liu C, Yang Z, Hu Y. Drought resistance of wheat alien chromosome addition lines evaluated by membership function value based on multiple traits and drought resistance index of grain yield. Field Crop Res. 2015;179: 103-12.

46. Zaifnejad M, Clark RB, Sullivan CY. Aluminum and water stress effects on growth and proline of sorghum. J Plant Physiol. 1997;150(3):338-44.

47. Purcell LC, Edwards JT, Brye KR. Soybean yield and biomass responses to cumulative transpiration: questioning widely held beliefs. Field Crop Res. 2007:101:10-8.

48. Li D, Liu H, Qiao Y, Wang Y, Cai Z, Dong B, Shi C, Liu Y, Li X, Liu M. Effects of elevated $\mathrm{CO}_{2}$ on the growth, seed yield, and water use efficiency of soybean (Glycine max L. Merr.) under drought stress. Agric Water Manag. 2013;129:105-12.

49. Adu MO, Asare PA, Yawson DO, Ackah FK, Amoah KK, Nyarko M, Andoh D. Quantifying variations in rhizosheath and root system phenotypes of landraces and improved varieties of juvenile maize. Rhizosphere. 2017;3:29-39.

50. Vadez V. Root hydraulics: the forgotten side of roots in drought adaptation. Field Crop Res. 2014;165:15-24.

51. Shan L, Yang C, Li Y, Duan Y, Geng D, Li Z, Zhang R, Duan G. Effects of drought stress on root physiological traits and root biomass allocation of Reaumuria soongorica. Acta Ecol Sin. 2015;35:155-9.

52. Chirino E, Ruiz-Yanetti S, Vilagrosa A, Mera X, Espinoza M, Lozano P. Morpho-functional traits and plant response to drought conditions in seedlings of six native species of ecuadorian ecosystems. Flora. 2017;233:58-67.

53. Serraj R, McNally KL, Slamet-Loedin I, Kohli A, Haefele SM, Atlin G, Kumar A. Drought resistance improvement in rice: an integrated genetic and resource management strategy. Plant Prod Sci. 2011;14:1-14.

54. Bengough AG, McKenzie BM, Hallett PD, Valentine TA. Root elongation, water stress and mechanical impedance: a review of limiting stresses and beneficial root tip traits. J Exp Bot. 2011;62:59-68.

55. Den HG, Van IG, Beeckman T, De SI. The roots of a new green revolution. Trends Plant Sci. 2010;15:600-7.

56. Lynch JP. Roots of the second green revolution. Aust J Bot. 2007:55:493-512.

57. Blum A. Breeding crop varieties for stress environments. Crit Rev Plant Sci. 1984;2:199-238.

58. Szira F, Balint AF, Borner A, Galiba G. Evaluation of drought-related traits and screening methods at different developmental stages in spring barley. J Agron Crop Sci. 2008;194(5):334-42.

59. Zadeh L. Fuzzy sets. Inf Control. 1965;8:338-53.

60. Fischer RA, Wood JT. Drought resistance in spring wheat cultivars III. Yield association with morphological traits. Aust J Agric Res. 1979;30:1001-20.

\section{Publisher's Note}

Springer Nature remains neutral with regard to jurisdictional claims in published maps and institutional affiliations.

Ready to submit your research? Choose BMC and benefit from:

- fast, convenient online submission

- thorough peer review by experienced researchers in your field

- rapid publication on acceptance

- support for research data, including large and complex data types

- gold Open Access which fosters wider collaboration and increased citations

- maximum visibility for your research: over $100 \mathrm{M}$ website views per year

At $\mathrm{BMC}$, research is always in progress.

Learn more biomedcentral.com/submissions 